\title{
Past time reference in a language with optional tense
}

\author{
M. Ryan Bochnak ${ }^{1}$
}

Published online: 1 September 2016

(C) The Author(s) 2016. This article is published with open access at Springerlink.com

\begin{abstract}
In this paper, I analyze the verbal suffix -uyil in Washo as an optional past tense. It is optional in the sense that it is not part of a paradigm of tenses, and morphologically tenseless clauses are also compatible with past time reference. Specifically, I claim that -uyil is the morphological exponent of a tense feature [PAST], which presupposes that the reference time of the clause, denoted by a temporal pronoun, precedes the evaluation time. Meanwhile, morphologically tenseless clauses lack a semantic tense restricting the value of the reference time pronoun. In comparing this analysis with one containing a covert non-future tense in morphologically tenseless clauses, I show that the range of empirical contexts that distinguish these analyses is quite narrow. However, I offer a novel argument against a covert tense analysis based on the lack of Maximize Presupposition effects. Crucially, the fact that -uyil does not form a paradigm of tenses results in a failure for Maximize Presupposition to apply. The proposed analysis places cross-linguistic variation at the level of the paradigm of tense features, namely whether they are present or absent, and if present, whether obligatorily so. This case study from Washo thus reveals what a language where tense features are optional can look like, and more generally contributes to the growing body of literature on cross-linguistic semantics devoted to uncovering the ways in which temporal interpretation can be achieved in natural language.
\end{abstract}

Keywords Tense - Optional tense - Embedded tense - Maximize Presupposition · Cessation implicatures · Washo

$\triangle$ M. Ryan Bochnak

ryan.bochnak@gmail.com

1 Department of Linguistics and English Language, University of Manchester, Samuel Alexander Building, Oxford Road, Manchester M13 9PL, UK 


\section{Introduction}

\subsection{Optional tense?}

Much work on cross-linguistic variation in tense systems has been devoted to the analysis of morphologically tenseless languages, i.e., languages that lack grammatical markers restricting the location of the reference time of a clause. ${ }^{1}$ Meanwhile, other cross-linguistic work has focused on variation between languages that have morphological tense systems. ${ }^{2}$ The picture that emerges from this work, at least implicitly, is one where there is a dichotomy between tensed and tenseless languages. On the one hand there are languages with tense paradigms where tenses are obligatory in finite clauses. On the other hand, there are languages that lack such morphemes altogether. In other words, tense appears to be an all-or-nothing category.

Such a state of affairs does not follow from a purely semantic perspective. Indeed, as work on temporal reference in both tensed and tenseless languages has shown, there is a variety of means by which the temporal reference of a clause may be identified, including tenses, but also temporal adverbs and contextual factors (see Tonhauser 2015 for a recent overview). Consider (1). The adverb yesterday locates the reference time on the day prior to speech time. The past tense on the verb dance is required by the morpho-syntax of English in this environment, even though in the presence of the adverb its semantic contribution is seemingly superfluous.

\section{(1) Yesterday, Kim danced.}

That is, from a semantic point of view, the past tense in (1) is not required to determine the reference time of the clause. Thus, in principle, we might expect to find languages that have morphological tenses that are not obligatory in cases where the reference time can be identified through other means, linguistic or contextual.

Such a possibility has recently been discussed in the typological work of Plungian and van der Auwera (2006). These authors identify several of the world's languages where the morphological marking of past temporal reference is optional. The optional tense markers in such languages tend to appear sporadically in discourses with past temporal reference, and morphologically tenseless clauses can also have a past interpretation. Not belonging to a full-fledged paradigm of tenses, these optional tense markers have a distribution quite different from tenses in languages like English. Plungian and van der Auwera nevertheless argue that such morphemes should be considered true tenses. This finding raises several interesting questions for the formal analysis of tenses, including the following: Do optional tenses have the same inter-

\footnotetext{
1 See for instance Baker and Travis (1997), Bittner (2005, 2014), Bohnemeyer (2002), Lin (2006), Matthewson (2006), Mucha (2013), Smith and Erbaugh (2005), Smith et al. (2007), Tonhauser (2011), among others.

2 I cannot do full justice to the vast literature on temporal reference in tensed languages, but a few works that explicitly aim to capture cross-linguistic variation include the following: Arregui and Kusumoto (1998), Bittner (2014), Bochnak and Klecha (2015), Grønn and von Stechow (2010), Hayashi and Oshima (2015), Klecha and Bochnak (to appear), Kubota et al. (2009, 2012), Mucha (2015), Ogihara (1989), Sharvit (2003, 2014) and Toosarvandani (to appear).
} 
pretation as tenses in languages with full, obligatory paradigms?; What does it mean for a tense to be optional?

In this paper, I aim to address these questions by investigating past temporal reference in Washo (Hokan/isolate; California and Nevada). In Washo, the verbal suffix -ujil is compatible only with past temporal reference, but morphologically tenseless clauses are also compatible with past temporal reference (Jacobsen 1964, 1996). For instance, the morphologically tenseless clause in (2) can have either a past or present temporal interpretation, ${ }^{3}$ whereas (3) can only have a past interpretation..$^{4,5}$

(2) háPaši

$\emptyset$-ha?aš-i

3-rain-IND

'It is raining.' / 'It rained.' / 'It was raining.'

(3) háPašunili

$\emptyset$-ha?aš-unil-i

3-rain-PAST-IND

'It rained.' / 'It was raining.'

I argue for an analysis of -uyil as a past tense, with a semantics parallel to that of past tense in languages like English. ${ }^{6}$ That is, the first question posed above receives a positive answer: past tense in Washo and English have the same interpretation, despite the past tense in Washo being optional. ${ }^{7}$ I furthermore argue that morphologically tenseless clauses such as (2) lack a tense feature that semantically restricts the location of the reference time. Thus, in response to the second question posed above, optional tense marking in Washo corresponds to optionality in whether a tense feature is present. In clauses with -ujil, there is a semantic tense feature [PAST]; in tenseless clauses, there is no tense feature.

In arguing that morphologically tenseless clauses contain no tense feature, I explicitly compare my analysis with one where a phonologically covert non-future tense feature is posited in morphologically tenseless clauses, following Matthewson (2006) for St'át'imcets. Such an analysis has initial plausibility because, as previewed in (2),

\footnotetext{
3 Morphologically tenseless clauses may also receive future interpretations in certain contexts; see Sect. 2.2 .

4 Examples (2) and (3) are presented 'out of context' for the purposes of exposition; further data used in this paper to substantiate the claims made are forthcoming in later sections.

5 A finite clause in Washo consists minimally of a verb stem inflected for person (prefixes) and a category that I refer to in this paper as mood (suffixes). Verb stems themselves may be morphologically complex, and may also be marked with negation, causative, or aspectual morphology (Jacobsen 1964, 1996). For the purposes of this paper, I will only use verb forms in the independent mood (-i), except where the dependent mood (-a?) is syntactically required, such as in the complement of propositional attitude verbs, and in temporal when-clauses; - $a$ ? is also the default mood marker in narrative contexts (Jacobsen 1964). I will also generally avoid using examples including aspectual morphology to control for the temporal effects of aspect. As indicated in the translations of (2) and (3), aspectually unmarked verb forms can receive perfective or imperfective interpretations. Orthographic and glossing conventions are listed in the appendix.

6 A formal framework for making this claim precise will be made explicit in Sect. 1.3.

7 In this respect, I concur with Cable (2016) in his recent analysis of a similar phenomenon in Tlingit; more on this in Sect. 6.
} 
morphologically tenseless clauses are restricted to past or present interpretations in most contexts. In fact, I will also show that even where morphologically tenseless clauses can receive a future interpretation, an analysis invoking a non-future tense makes the same predictions as my analysis in a number of cases. I then offer a novel argument against a non-future tense analysis based on the pragmatic blocking principle Maximize Presupposition (Heim 1991; Percus 2006; Schlenker 2012, among others). This principle implores a speaker to use a sentence with the strongest presupposition compatible with her knowledge. Since the presupposition of a past tense is stronger than the presupposition of a non-future tense, Maximize Presupposition predicts the past tense to be used whenever its presupposition is satisfied, contrary to fact. I propose that tenseless and -unil-marked clauses are not the right sort of competitors to enter into a Maximize Presupposition competition. Under my analysis, the fact that -unil is not a member of a paradigm of tenses is crucial, and effectively prevents the pragmatic competition between tensed and tenseless clauses. This study thus indirectly sheds light on the nature of presuppositional alternatives, which, to my knowledge, has only been explored in well-studied Indo-European languages such as English, German, and French.

This paper proceeds as follows. In Sect. 2, I describe the interpretation of morphologically tenseless clauses, and in Sect. 3 the interpretation of clauses containing -uyil. In Sect. 4, I present my analysis of both morphologically tenseless clauses, and clauses containing -uyil. Then in Sect. 5, I present my novel argument for a tenseless analysis of morphologically tenseless clauses based on Maximize Presupposition. In Sect. 6, I discuss an apparent counter-argument to my claim that -ujil is simply a past tense, namely the observation that it often gives rise to a cessation inference in addition to its vanilla past tense meaning. I argue that such inferences are conversational implicatures, which may be cancelled, and thus not part of the conventional meaning of -uyil. Section 7 outlines further issues in past temporal reference in Washo to be explored in future research, while Sect. 8 concludes. In the remainder of this section, I outline the methodology used in this paper, and lay out the details of the formal framework within which I couch my analysis.

\subsection{Methodology}

Unless otherwise indicated, the data for this paper come from my own primary fieldwork with two Washo elders, Steven James and the late Ramona Dick. Both learned Washo natively growing up, although English is today the main language of communication within the Washo community. The working language for conducting interviews with speakers was English. Unless otherwise stated, a sentence presented without a diacritic signals that both speakers have judged the sentence as acceptable in the context provided. In an acceptability judgment task, the researcher presents a context (usually orally in this case) to a speaker, and then presents a Washo sentence to the speaker, and asks if the sentence sounds ok in that context. I use \# to indicate that a sentence was not accepted by speakers in the context provided, and ? to indicate variation between speakers. Sentences taken from the Washo reference grammar (Jacobsen 1964) are adapted to the glossing conventions and slightly modified orthography used in this 
paper. Examples taken from texts are presented with contextual information about the plot at the time when the example appears. The texts were collected, transcribed, and translated by Dr. William Jacobsen Jr. in the 1950s with Washo speakers Bertha Holbrook, Hank Pete, and John Wiger. The texts (recordings and transcriptions) are available from the California Language Archive (http://cla.berkeley.edu). I assume that attestation in a text is tantamount to a positive acceptability judgment of a native speaker.

\subsection{Formal background on tense}

Before continuing, I outline my assumptions about the formal framework I will be using to make my claims and analysis precise. As is standard, I take tenses to constrain the relation between utterance time (UT) and reference time (RT), while aspects constrain the relation between eventuality time (ET) and reference time (Klein 1994; Reichenbach 1947). The need for three distinct times can be illustrated with the English past perfect as in (4):

(4) When we arrived at Steven's house, he had already left.

Here, UT is the speech time, while ET of the main clause is the time of Steven's leaving, and RT is the time named by the when-clause, i.e., the time of our arrival at Steven's house. Thus, the past tense in the main clause locates RT in the past of UT, while the perfect aspect locates ET in the past of RT.

Furthermore, I assume a pronominal/referential theory of tense, whereby the RT of a clause is represented as a temporal pronoun (Abusch 1997; Heim 1994; Kratzer 1998; Partee 1973). Being a pronoun, it bears an index $i$, and receives its value from an assignment $g$. A tense feature, then, is interpreted as a partial identity function, which places a presupposition on the possible values of the temporal pronoun to which it is adjoined. I illustrate with the English example in (5). The $\mathrm{T}$ head in (5a) bears the index 1 , and receives its value from the assignment $g$ as in $(5 \mathrm{~b}-\mathrm{i})$. The feature [PAST] is a partial identity function that introduces the presupposition that the reference time denoted by $\mathrm{T}_{1}$ is located before the utterance time $t_{c}$, shown in (5b-ii). I assume that the sister to $\mathrm{T}^{\prime}$ denotes a predicate of times, as in $(5 \mathrm{~b}-\mathrm{iii}) .{ }^{8}$ The temporal pronoun then saturates the temporal argument, returning the proposition in $(5 \mathrm{~b}-\mathrm{iv}) .^{9}$

(5) Ramona arrived.

a. Syntax:

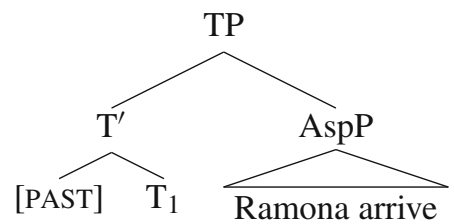

\footnotetext{
${ }^{8}$ I refer to this node as AspP, as is standard, although I will mostly abstract away from the contribution of aspect in this paper.

${ }^{9}$ I assume an LF-based framework in the style of Heim and Kratzer (1998). Temporal precedence is abbreviated with the symbol $<$.
} 
b. Semantics:

i. $\llbracket \mathrm{T}_{1} \rrbracket^{g, c}=g(1)$

ii. $\llbracket \mathrm{PAST} \rrbracket^{g, c}=\lambda t: t<t_{c} \cdot t$

iii. $\llbracket \mathrm{AspP} \rrbracket^{g, c}=\lambda t \lambda w$.arrive $(r)(t)(w)$

iv. $\llbracket \mathrm{TP} \rrbracket^{g, c}=\lambda w$ arrive $(r)(g(1))(w)$; defined only if $g(1)<t_{c}$

Thus, under this view there are two pieces that correspond to what we know as tense in a language like English: a temporal pronoun denoting the reference time, and a feature that restricts the value of that pronoun.

With this background in place, I will re-state my proposal about optional tense in Washo and foreshadow my analysis within this framework. First, -unil in Washo is the morphological exponent of the feature [PAST], and receives the same interpretation as the English past tense in (5). Second, in morphologically tenseless clauses, tense features are absent. Although I still posit a temporal pronoun denoting the reference time in such cases, its value is not semantically restricted by a tense feature. ${ }^{10}$ The bipartite nature of tense in this framework thus allows us to tease apart the reference time of a clause from the features that constrain its value, and make a more nuanced claim about what exactly is optional in an 'optional tense' language.

\section{The interpretation of morphologically tenseless clauses}

\subsection{Past and present interpretations of unmarked matrix clauses}

In this section, I outline the interpretation of morphologically tenseless clauses in Washo, starting with matrix clauses. As I have already indicated, such clauses are readily compatible with either present or past interpretations. In particular, they are compatible with both present- and past-oriented adverbials, as shown in (6)-(7).

(6) wá:din wayák’aši

wa:din w-yak'aš-i

now STATIC-warm-IND

'It (the weather) is warm now.'

(7) watlí: zírgin lébikhayi

watli: zirgin le-ibik'-ha-i

morning chicken 1-be.cooked-CAUS-IND

'I cooked chicken this morning.'

Importantly, lexical aspect (Aktionsart) does not entail a particular temporal reference. For instance, whereas (6) contains a state with present temporal reference, (8) and (9) contain states (bišapu? 'hungry', i i 'exist', and belewe? 'be lying around') with past temporal reference. Meanwhile, (10) and (11) both contain the same verb

\footnotetext{
10 This aspect of the analysis parallels Mucha's (2013) analysis of the morphologically tenseless language Hausa.
} 
stem gama? 'eat up', an accomplishment, although the temporal reference is present in (10) and past in (11). ${ }^{11}$

(8) a. Context: What did you eat for dinner last night?

b. léw dibišápuPišya démluna dánala

le-w di-bišapu?-i-š-na d-emlu-na dạal-a

1PRO- PL 1-hungryIND-SR-but D.POSS-eat-NC house-LOC

PiPiyérsi

2-i?i-ers-i

3-exist- NEG- IND

'We were hungry, but there was no food in the house.'

(9) a. Context: In the Spring, some Washos arrived at where the Donner Party had set up camp the previous Autumn.

b. t'ánuyuyil Píhep t’áyuš datóPya

t'anu-unil Piheb t'-ayuš de-tó?o-a

person-dead head 3.POSS-hair 3.POSS-throat-LOC

dagumyá:k'ima?yigiš be?léwe?iš

de-gum-ya:k' ’m-a?yi?-i-š Ø-be?lewe?-i-š

NMLZ- REFL-cut-MIR-IND-SR 3-lie.around-IND-SR

'The dead people's heads and hair, which were cut off at their throats, were lying around.'

(Donner Expedition story)

(10) a. Context: You just finished dinner, and everyone left the kitchen except for Mona. You ask someone what she is up to now. They tell you:

b. zí:gin hénuy guwáwa?išge mó:na míPle? gáma?i

zirgin henuy Ø-guwawa?-i-š-ge mo:na mi?le? Ø-gama?-i

chicken little.bit 3-remain-IND-SR-OBJ.REL Mona all 3-eat.up-IND

'Mona is eating up all the little bits of chicken that are left over.'

(11) a. Context: You just finished dinner; chicken was served, your favorite food.

b. zírgin digáma?i

zirgin di-gama?-i

chicken 1-eat.up-IND

'I ate up the chicken.'

The reference time of a morphologically unmarked clause can be anaphoric to a time previously mentioned in the discourse, for example to a time named by a whenclause. In (12)-(13), the RT-setting clause is also morphologically tenseless, while in (14), a time introduced in a clause containing -unil 'past' serves to set the RT of the tenseless clause.

(12) a. Context: A mother bear was about to go out to gather food, leaving her children behind.

\footnotetext{
11 The appearance of -unil on the noun t'ánu 'person' in (9) is a different use of this morpheme than the one analyzed in this paper; see Sect. 7 for comments on nominal uses of -unil.
} 
b. mušérgew Plémi?gišuwa?áša?a? muše:gew $\emptyset$-Plemi?-giš-uwe?-aša?-a? bear 3-gather.food-along-hence-PROSP-DEP 3.POSS.REFL-child PL bó:yiyige wehigírgithaya? $\emptyset$-bo:ni-i-ge $\emptyset$-wehigirgit-ha-a? 3-call-IND-OBJ.REL 3-show.how-CAUS-DEP

'When the bear was about to go gathering food, she called out to her children, whom she told what to do.'

(Bear and Deer story)

(13) a. Context: Coyote made a fire to smoke out Lizard, who was hiding in a crack in a rock.

b. bemú:k'ida? díPyuya Paš $\emptyset$-bemu:k'id-a? di?yu-a ?-a?-š sigí:giya?

3-spit-DEP fire-LOC THEME-DEP-SR 3-sizzle-DEP

'When he [Coyote] spit into the fire, it sizzled.' (Coyote and Lizard story)

(14) a. Context: Some Washos arrived at where the Donner Party had set up camp.

b. gesú:dumuyiludi ge-su:dum-unil-ud-i t’ánuya Pe?ésisiš 3.OBJ-look.for-PAST-SEQ-IND person-NC 3-COP-NEG-IND-SR

'They looked for them, but no one was there.' (Donner Expedition story)

The first clause of (12) furthermore shows that we are dealing with reference times rather than eventuality times. Here, the prospective aspect - $a \check{a} a$ ? places the event of the bear going to gather food after the reference time. In this case, RT and ET do not overlap. A bit later in the story, we find out that the bear goes to gather food, indicating that $-a \check{a} a ?$ is not a future tense, i.e., - $a \check{s} a$ ? does not place RT in the absolute future of UT.

For completeness, and for the sake of cross-linguistic comparison, I also show here that morphologically tenseless clauses can refer to a reference time interval that spans both the past and present. ${ }^{12}$ In both (15) and (16), a plurality of events whose time trace spans both the past and present are described using a single morphologically tenseless verb form. ${ }^{13}$

(15) a. Context: Your son is in the next room reading, so you're watching his kids in the living room. First, Ramona starts jumping around, so you tell her to stop, and she does. Then, Jonathan starts jumping around, and your son comes in to ask what all the noise is about. You tell him ...

\footnotetext{
12 Matthewson (2006) first showed that such examples were possible for morphologically tenseless clauses in St'át'imcets, and subsequent research has shown that these are also possible in Hausa (Mucha 2013) and Tlingit (Cable 2016). The context for (15) is adapted from Cable (2016), and the context for (16) is adapted from Mucha (2013).

13 Parallel sentences where a morphologically tenseless clause can have a reference time that overlaps the past, present and future seem to not be possible. This doesn't seem too surprising, however, since future interpretations typically require an overt future or modal, or a very specialized context, as will be shown in the following subsection.
} 


\section{b. melepépsi Ramonahak'a Jonathan}

Ø-melepeps-i Ramona-hak'a Jonathan

3-jump.PL-IND Ramona-with Jonathan

'Ramona and Jonathan were/are jumping.'

(16) a. Context: Ramona and Jonathan have only one guitar, so they have to take turns playing. First, Ramona plays, and then she gives the guitar to Jonathan. While Jonathan is playing, your son walks in and asks who is making all the noise, since it's disturbing his reading. You say ...

b. Jonathanhak'a Ramona mámaya gú?uši?i

Jonathan-hak'a Ramona mamaja Ø-gu?uši?-i

Jonathan-with Ramona noise 3-make-IND

'Jonathan and Ramona were/are making noise.'

In sum, morphologically tenseless matrix clauses are compatible with both past and present reference times. Those reference times may be named by a temporal adverbial, or they may be anaphoric to a time made available from the context, e.g., a time introduced in a previous clause. This state of affairs is compatible with my claim that such clauses do not contain a tense feature that semantically restricts the value of RT.

Let us now turn to future interpretations of tenseless matrix clauses. As we will see, although future temporal reference is often dispreferred for unmarked clauses, future interpretations are licensed in certain environments.

\subsection{Future interpretations of morphologically tenseless clauses}

Morphologically tenseless clauses often resist a future interpretation. For instance, speakers judge co-occurrence with the future-oriented adverb wádiy dewp'áwit 'tonight' in (17) as unacceptable. Instead, speakers prefer to have an overt future marker, such as the prospective aspect -aša? in (18). ${ }^{14}$

(17) a. Context: I ask you what the weather will be like later today.

b. \# wá:din dewp'áwit há?aši

wa:din dewp' awìd Ø-ha?aš-i

today evening 3-rain-IND

Intended: 'It will rain tonight.'

(18) a. Context: I ask you what the weather will be like later today.

b. wádin dewp'áwit há?ašaša?i

wadin dewp'awid Ø-ha?aš-aša?-i

today evening 3-rain-PROSP-IND

'It's going to rain tonight.'

14 There are two other future markers in Washo: -ti? 'intermediate future' and - $g a b$ 'distant future', which additionally make remoteness distinctions (Jacobsen 1964). Since those markers are also subject to particular licensing conditions, and future time reference is not the main focus of this paper, I leave their exact characterization and analysis to another occasion. 
However, future interpretations of morphologically tenseless clauses are not systematically absent. For instance, (19) shows a question-answer pair regarding dinner plans in the future of the utterance time, but without any future marking. (20) is a similar example, and shows that the future interpretation is not derived from the lexical meaning of the verb do:da 'make', and that these types of sentences can be used to talk about a third person's plans.

(19) Context: A conversation between A and B about plans for dinner this evening.

A: hut'anahé:š Pumdó:da?i dewp’áwit démlulewe

hut'ana-he:š ?um-do:da?-i dewp'awid d-emlu-lewe

what-Q 2-make-IND evening D.POSS-eat-for

'What will you prepare for dinner?'

B: šú:pk'ey lí: didó:da?i

šu:p-k'en li: di-do:da?-i

soup-RESTR PRT 1-make-IND

'I'll just make soup.'

(20) a. Context: You want to know what Mona will cook for dinner later today.

b. hut'ayahé:šs mó:na Pí:bikhayi dewp'áwit démlulewe

hut'ana-he:š mona ?-i:bik'-ha-i dewp'awid d-emlu-lewe

what-Q Mona 3-be.cooked-CAUS-IND evening D.POSS-eat-for

'What will Mona prepare for dinner?'

Such examples are admittedly quite rare, and while both speakers accepted dialogues of this sort, there is definitely a preference to mark future-oriented matrix clauses with some sort of future morphology. The fact that a plan is at issue in (19) and (20) seems crucial for licensing the future reading here, and I will make use of this fact when analyzing these clauses in Sect. 4.2.1.

Another case where we find morphologically tenseless clauses with future temporal reference is shown in (21)-(22), where a series of conjoined clauses receive future interpretations without any future morphology. Notably, the first two clauses contain the sequential morpheme $-u d$, which serves to indicate forward progression in a narrative, similar to English 'then'. In (21), the event of sleeping in the first clause is in the future of the utterance time. Only the final clause is marked with the intermediate future - $t i$ ?, while the first clause contains sequential - $u d$. In (22), Mother Bear is giving instructions to her children about what they are supposed to do when she leaves to gather food. No overt future markers are present in any of the clauses, even though the events described are to occur in the future of the utterance time. ${ }^{15,16}$

(21) a. Context: The baby has been feeling sick, and is very cranky. You think that if she has a nap she will feel better.

\footnotetext{
15 Note that the clauses in (22b) are not imperatives, but regular declarative sentences with second person subjects. Imperatives are formed with a verbal prefix ge-, and no mood suffix on the verb; see Jacobsen $(1964,1996)$.

16 It is common to find clausal conjunctions where one of the clauses is marked with a future morpheme and the other clauses are unmarked, as shown in (21); however, (22) shows that this is not necessary for future interpretation.
} 
b. Pélšimánawudi hamuPayawšémuya?

?-elšim-?ayaw-ud-i Ø-hamu-Payaw-šemu-a?

3-sleep-good-SEQ-IND 3-feel-good-really-DEP

Pémc'itigi

P-emc'i-ti?-i-gi

3-wake.up-INT.FUT-IND-SUBJ.REL

'After she has a good sleep, she will wake up feeling good.'

(22) a. Context: Mother Bear is about to go out gathering food. She tells her children what to do when she is gone.

b. léyewe?udiš há:Pdawí?ši memdérwi ga?míPmin

le-iyewe?-ud-i-š ha:?da wi?-ši memderwi ya?min $\sim$ RED

1-go- SEQ- IND- SR there 3.PRO- DU deer child $\sim$ PL

Pumdó:bašhayudi lé: mimdác'awéwahayaš

?um-do:baš-ha-ud-i le: mi-Pumdac'awewe-ha-a?-š

2-burn-CAUS-SEQ-IND 1.PRO 2-pound.up.meat-CAUS-DEP-SR

'After I go, you'll burn those two deer children to death and then pound them up for me.'

(Bear and Deer story)

Importantly, $-u d$ does not entail absolute future time reference on its own, since it also occurs in clauses with past temporal reference to indicate narrative progression. For instance, we find sequential - $u d$ in (23), where the morphologically tenseless clauses have past temporal reference.

(23) a. Context: You're telling me about yesterday's weather.

b. háPašudi déPešgána?i

$\emptyset$-ha?aš-ud-i Ø-de?eš-gaya?-i

3-rain-SEQ-IND 3-snow-begin-IND

'It was raining, and then it began to snow.'

Another case where future interpretations of morphologically tenseless clauses are licensed is in conditional antecedents, as will be shown in the next subsection.

In sum, morphologically tenseless clauses can receive past, present, and in limited cases future temporal reference.

\subsection{The interpretation of embedded tenseless clauses}

Here I briefly describe the interpretation of morphologically tenseless clauses in embedded environments. A more general discussion of the temporal interpretation of embedded clauses is postponed until Sect. 3.2, after I have introduced the interpretation of clauses marked with -uyil.

\subsubsection{Relative clauses}

Morphologically tenseless relative clauses can receive either a "back-shifted" or "simultaneous" interpretation relative to the matrix eventuality time. In (24), the context provides a past RT situated some time in the week prior to speech time. The 
event of people coming to the party is therefore located in the past of speech time in this morphologically tenseless clause. The embedded clause is likewise morphologically tenseless, but is interpreted temporally prior to the eventuality time of the matrix clause; the inviting to the party occurs prior to the arriving at the party.

(24) a. Context: You are telling me about a party you hosted last week.

$\begin{array}{lll}\text { b. míPlew } & \text { dibóniyišgi } & \text { Píbi?i } \\ \text { mîle?-w } & \text { di-boni-i-š-gi } & \text { ?-i:bi?-i }\end{array}$

every-HUM.PL 1-invite-IND-SR-SUBJ.REL 3-come-IND

'Everyone who I invited came.'

(embedded RT < matrix ET)

In (25), the reference time of the main clause, which is morphologically tenseless, is the time of Mother Bear searching for her children, in the past of speech time. The RT of the embedded clause, also morphologically tenseless, is simultaneous with that time.

(25) a. Context: Mother Bear is searching for the deer who killed her children. She comes across a heron sitting by the river.

b. k'á:k'a? dá: gérgelišge yá:ma?

k'a:k'a? da: Ø-ge:gel-i-š-ge Ø-ya:m-a?

heron there 3-sit-IND-SR-OBJ.REL 3-talk-DEP

'She spoke to a heron who was sitting there.'

(embedded RT = matrix ET)

(Bear and Deer story)

Thus, morphologically tenseless relative clauses can receive an interpretation which is either back-shifted or simultaneous relative to a morphologically tenseless main clause with past temporal reference.

\subsubsection{Complement clauses}

A morphologically tenseless complement clause can receive a temporal interpretation simultaneous to the eventuality time of a morphologically tenseless matrix clause. In (26), the time of being named Tim is simultaneous with the time of thinking, which is in the past of speech time, given the context. In (27), the time of being sick is simultaneous with the time of thinking, also in the past of speech time, given the context.

(26) a. Context: You see a man in the street and say 'Hi Tim!' He tells you his name isn't Tim. You apologize, and say:

b. Tim degumdíPye? Méra? dihámuyi

Tim de-gum-di?ye? M-e?-a? di-hamu-i

Tim NMLZ-REFL-name 2-COP-DEP 1-think-IND

'I thought your name was Tim.'

(embedded $\mathrm{RT}=$ matrix $\mathrm{ET} \rightarrow$ simultaneous reading) 
(27) a. Context: I was going to pick you up to do language work earlier today, but your son said you were sick. I decide to come visit you anyways, to see if I can help you while you're sick. When I arrived at your house, it turned out you weren't sick. Later on, you say:

b. watlí: milígigibi?i diyáhaya? Pumhámuyina

watli: mi-le-irgi-gibi?-i di-yaha-a? ?um-hamu-i-na

morning 2-1-see-come-IND 1-sick-DEP 2-think-IND-but

'This morning you came to see me, but you thought I was sick.' (embedded $\mathrm{RT}=$ matrix $\mathrm{ET} \rightarrow$ simultaneous reading)

Meanwhile in (28), the matrix RT and overlapping ET are located in the present, while the embedded RT is in the past of the matrix ET. In (29), the past time of playing cards in the embedded clause precedes Steven's thinking time.

(28) a. Context: You arrive home from shopping, and find that the chicken you had cooked before you left is gone. As far as you know, only your son has been at home.

b. dịá:m zí:gin hé:š Pí?wa? dihamuguyú:gi

di-na:m zi:gin he:š P-i?iw-a? di-hamuguyurg-i

1.POSS-son chicken Q 3-eat-DEP 1-wonder-IND

'I wonder if my son ate the chicken.'

(embedded RT < matrix ET $\rightarrow$ back-shifted reading)

(29) a. You run into Steven in the street, and he asks you about how your card game went on Friday. You tell him that you didn't play cards on Friday. Later, when you see me, you say ...

b. Steven dimóndegišuwe?a?

Steven di-monde-giš-uwe?-a?

githámuya? Pídi

git-hamu-a? ?-id-i

Steven 1-play.cards-along-hence-DEP 3.REFL-think-DEP 3-say-IND

'Steven said he thought I went to play cards.'

(embedded RT 'playing cards' < matrix ET 'think' $\rightarrow$ back-shifted reading)

\subsubsection{Antecedent of conditionals}

The antecedent of a conditional is an embedded environment where a morphologically tenseless clause can receive a temporal interpretation in the absolute future of the utterance time. For instance, the context of (30) sets up a future reference time of the day following utterance time. In (31), the future-oriented adverb wát 'tomorrow' co-occurs with a morphologically tenseless clause in the antecedent. ${ }^{17}$

(30) a. Context: We are discussing our plans for tomorrow, which are dependent on the weather.

17 See Bochnak (2015) for some brief comments on the structure and interpretation of conditionals in Washo. 
b. wayák'ašiš dáPaw Rárga?a léyowegabigi

w-yak'aš-i-š da?aw Rarga?-a le-iye?-uwe?-gab-i-gi

STATIC-warm-IND-SR Lake Tahoe-LOC 1-go-hence-FUT-IND-SUBJ.REL

LéPi

Le-é?-i

1-MOD-IND

'If it's warm, we will/might go to Lake Tahoe.'

(31) a. Context: We are discussing our plans for tomorrow, which are dependent on the weather.

b. wát há:bi?iš lí:nuya léyowe?érsheligi

wat ha:bi?-i-š li:nu-a le-iye?-uwe?-ers-hel-i-gi

tomorrow rain-IND-SR Reno-LOC 1-go-hence-NEG-SBJ-IND-SUBJ.REL

LéPi

Le-e?-i

1-MOD-IND

'If it rains tomorrow, we might not go to Reno.'

Whereas morphologically tenseless matrix clauses typically resist future interpretations, even with future-oriented adverbs [see (17)] such interpretations are readily available for the antecedent of conditionals.

Furthermore, the reference time of the antecedent clause may be in the future of the reference time of the consequent. This is shown in (32).

(32) a. Context: Herman is expecting his cousin to come some time this week, but you don't know exactly when. But if his cousin is going to arrive tomorrow, then Herman must be happy now.

b. wát Herman Píryelu? Píbi?iš wá:din

wat Herman ?-i:yelu? ?-ibbi?-i-š wa:din

tomorrow Herman 3-cousin 3-come-IND-SR now

hamu?ánawigi k'é?i

$\emptyset$-hamu-Payaw-i-gi k'-e?-i

3-feel-good-IND-SUBJ.REL 3-MOD-IND

'If Herman's cousin comes tomorrow, he is happy now.'

In sum, the data from embedded contexts is consistent with the hypothesis that morphologically tenseless clauses in Washo contain no semantic tense restricting temporal reference.

\section{The interpretation of clauses marked with -uyil}

\subsection{The interpretation of -uyil in matrix contexts}

Clauses containing -unil are only compatible with past time reference. In (33), a verb marked with -ujil co-occurs with the past-oriented adverb watlí: 'this morning', which speakers judge acceptable. By contrast, speakers judge (34) and (35) unacceptable, 
where a verb marked with -uyil co-occurs with the adverbs wá:din 'now' and wát 'tomorrow', respectively.

(33) watlí: wánawuyili

watli: w-anaw-unil-i

morning STATIC-good-PAST-IND

'It (the weather) was nice this morning.'

(34) \# wá:din há?ašunili

wa:din Ø-ha?aš-unil-i

now 3-rain-PAST-IND

Attempted: 'It's raining now.'

$\begin{array}{ll}\text { \# wát } & \text { há?ašuyili } \\ \text { wat } & \emptyset \text {-ha?aš-unil-i } \\ \text { tomorrow } 3 \text {-rain-PAST-IND } \\ \text { Attempted: 'It will rain tomorrow.' }\end{array}$

In the absence of temporal adverbs, -uyil is also only compatible with past reference times. For instance in (36), repeated from above, the context makes salient the past time when the Washos arrived at the Donner Party camp, and -uyil is used. Meanwhile, in (37), the context makes the speech time salient, and speakers find the sentence unacceptable in the context.

(36) a. Context: In the Spring, some Washos arrived at where the Donner Party had set up camp.

b. gesú:dumuniludi ge-su:dum-unil-ud-i

$$
\begin{array}{ll}
\text { t'ánuya } & \text { PePéssiš } \\
\text { t'anu-na } & \text { P-e?-ers-i-šs }
\end{array}
$$

3.OBJ-look.for-PAST-SEQ-IND person-NC 3-be- NEG- IND- SR

'They looked for them, but no one was there.' (Donner Expedition story)

a. Context: It's noon, and I ask you what your son is up to now. It turns out that he has been sleeping all day, and in fact he is still asleep!

b. \# dijá:m Pélšimunili

di-na:m P-elšim-unil-i

1.POSS-son 3-sleep-PAST-IND

Intended: 'He is sleeping.'

These data are compatible with the hypothesis that -uyil is a past tense, restricting the reference time to the past of the evaluation time (i.e., speech time in matrix clauses).

Verbs marked with -uyil can anaphorically refer to a past reference time. In (38), the reference time of the clause léyowe Pérsunili 'I didn't go' is anaphoric to the past time of playing cards made salient by the context and the previous clause. In the dialogue in (39), the reference time of speaker B's response is anaphoric to the time asked about by speaker A, i.e., the time immediately before speaker A called.

(38) a. Context: I know you usually go to the Seniors' Center to play cards on Friday, and I ask if you went last week. 

b. t'ánu mónde?išda
léyowe Pé:sunili
t'anu $\emptyset$-monde?-i-š-da
le-iyowe?-e:s-unil-i
person 3-play.cards-IND-SR-there 1-go-NEG-PAST-IND
'People were playing cards there, but I didn't go.'

(39) Context: I call you up in the afternoon, and I ask what you were up to before I called.
A: hút'ana hé:š Pumdó:da?unili
hut'ana he:š ?um-do:da?-unil-i
what Q 2-do-PAST-IND
'What were you doing?'
B: didulék'ilunili
di-dulek'il-unil-i
1-cook-PAST-IND
'I was cooking.'

Evidence that -unil locates reference time as opposed to eventuality time comes from the interaction with prospective aspect. For instance in (40), the reference time is set up in the context as the past time that Steven was looking for his lottery ticket, whereas the eventuality time of winning money is in the future of that time, which is marked with the prospective aspect marker -aša?.

(40) a. Context: Steven had the winning numbers in the lottery, but when he went to look for his ticket, he couldn't find it anywhere.

b. t'é:k'e? heyéPemaša?uyilaš gitbehúwe? páyhayi

t'e:k'e? Ø-heye?em-aša?-unil-a?-š git-behuwe? Ø-pay?-ha-i

much 3-win-PROSP-PAST-DEP-SR REFL-ticket 3-lose-CAUS-IND

'He was going to win a lot of money, but he lost his lottery ticket.'

There is also evidence that - unil is not a terminative aspect, based on the diagnostics of Bohnemeyer (2002). First, according to Bohnemeyer terminative aspects should allow past perfect readings with reference-time-setting adverbs or past-oriented whenclauses, which is not the case for -ujil. For instance, a past perfect interpretation for -uyil in (38) is not possible, even though the context sets up that the speaker had gone to the Seniors' Center before last Friday. Second, the interruption of the post-state of an event is fine for -uyil, as in (41), whereas this is not possible for terminative aspects (cf. English Perfect: \#I have lost my glasses, and now I found them). ${ }^{18}$

(41) a. Context: I ask what your son has been up to all day.

b. Pélšimuniludi p'ík’iwleludi yása? lí:

?-elšim-unil-ud-i Ø-pik'iwlel-ud-i yasa? li:

3-sleep-PAST-SEQ-IND 3-wake.up-SEQ-IND again PRT

Pelšimgayabuwe?i

2-elšim-gayab-uwe?-i

3-sleep-start-hence-IND

'He was sleeping, then he woke up, and then he went to sleep again.'

$\overline{18}$ Note, however, that the past perfect in English works here: I had lost my glasses, but then I found them. 
Since -uyil behaves like a tense in the relevant respects, including having anaphoric uses, and relating reference time to utterance time, I conclude that it should be analyzed as a past tense.

\subsection{The interpretation of -uyil in attitude complements}

Before going on to my analysis, let us first consider the interpretation of -uyil in attitude complements. What we find is that -ujil embedded under propositional attitude verbs gives rise to the same types of readings as the English past tense, specifically so-called Sequence of Tense (SOT) effects (Ogihara 1989).

The observation for English is that a past tense stative embedded under a past tense attitude verb can receive two readings, as in (42): a "simultaneous" reading, where the state of being sick holds at the time of saying, and a "back-shifted" reading, where the state of being sick is in the past of the time of saying.

(42) Katie said that Nico was sick.

a. Katie said: "Nico is sick."

b. Katie said: "Nico was sick."

$$
\begin{aligned}
& \text { "simultaneous" reading } \\
& \text { "back-shifted" reading }
\end{aligned}
$$

Under Ogihara's influential analysis, an embedded tense is optionally deleted under identity with a c-commanding matrix tense. Cross-linguistic research has shown that there is variation in whether languages make use of such a SOT rule, and also in which embedded environments such a rule applies (e.g., Arregui and Kusumoto 1998; Grønn and von Stechow 2010; Kubota et al. 2009, 2012; Ogihara 1989; Sharvit 2014). Furthermore, there is somewhat of a debate as to whether a SOT rule, which is syntactic in nature, should be used or is necessary to account for a seemingly semantic phenomenon (Altshuler and Schwarzschild 2012; Gennari 2003; Kubota et al. 2009, 2012; Sharvit 2014). An analysis of the temporal interpretation of attitude complements in Washo is forthcoming in Sect. 4. For now we observe that the data for Washo -uyil pattern remarkably similar to the facts for the English past tense. Note that throughout this subsection, I exclusively focus on past interpretations of -uyil-marked and morphologically tenseless clauses.

A simultaneous reading is available for a stative predicate marked with -uyil embedded under an attitude verb also marked with -uyil, as shown in (43). When presented with the context in (43a), a speaker volunteered the form in (43b). This shows that the simultaneous reading is available, since the context provides that the time of being named Tim is simultaneous with the time of thinking the addressee's name is Tim (since, presumably, the speaker would only say "Hi Tim!" if she thought the addressee's name was Tim at that time). ${ }^{19}$

\footnotetext{
19 I am purposely using an individual-level state in the embedded clause. The reason is that individuallevel predicates are temporally stable, meaning that a back-shifted reading whereby the embedded state no longer holds should be implausible without a special context. This is exactly what appears to be going on, as the examples in this section show, especially (44). We are thus able to detect back-shifted readings quite
} 
(43) a. Context: You see a man in the street and say 'Hi Tim!' He tells you his name isn't Tim. You apologize, and say:

b. Tim degumdírye? MéPunila? dihámuyujili

Tim de-gum-di?ye? M-e?-unil-a? di-hamu-ujil-i

Tim NMLZ-REFL-name 2-COP-PAST-DEP 1-think-PAST-IND

'I thought your name was Tim.'

(embedded $\mathrm{RT}=$ matrix $\mathrm{ET} \rightarrow$ simultaneous reading)

However, when I first tried to replicate this pattern with another speaker, his reaction indicated that the back-shifted reading for embedded -unil was not only possible, but more salient, as shown in (44c). The speaker's reaction and volunteered commentary indicate that he does not interpret the time of being named Tim as overlapping with the time of thinking. ${ }^{20}$

(44) a. Context: You see a man in the street and say 'Hi Tim!' He tells you his name isn't Tim. You apologize, and say:

b. Tim degumdíPye? MéPunila? dihámuyujili

Tim de-gum-di?ye? M-e?-unil-a? di-hamu-unil-i

Tim NMLZ-REFL-name 2-COP-PAST-DEP 1-think-PAST-IND

c. Speaker: (laughing) "Sounds like Tim used to be your name."

MRB: "Like he changed his name?"

Speaker: "Yeah."

Upon discussing this example further with this speaker, he did later accept the same judgment that (43) could also be used in this context that favors the simultaneous reading. So while the the back-shifted reading is possible for-uyil embedded under unil, the simultaneous reading is also available. Another example showing that the simultaneous reading is available for an embedded stative predicate marked with -uyil is in (45), which was accepted by both speakers (modulo gender differences; the example here is shown for the male speaker). In the context provided, the backshifted reading is in fact quite implausible. ${ }^{21}$

Footnote 19 continued

straightforwardly by relying on the lexical inferences associated with individual-level predicates. This point is also important for cross-linguistic comparison, since Tonhauser (2011) shows that only a simultaneous reading is possible for embedded clauses in the tenseless language Paraguayan Guaraní.

Note, however, that the same patten holds for stage-level states as well, such as (1).

(1) a. Context: Ryan said yesterday that Steven had been sick last week.

b. Steven yáhayuyila? Ryan Pí:dunili

Steven Ø-yaha-unil-a? Ryan ?-i:d-unil-i

Steven 3-be.sick-PAST-DEP Ryan 3-say-PAST-IND

'Ryan said Steven was sick.'

20 A reviewer remarks that using think in the past tense with a first person subject is often used to convey a meaning that can be paraphrased as "I now know that ... not ...." The examples provided in (1) in footnote (19) and in (45) mitigate against this worry.

21 The context for (45) is adapted from Cable (2016). 
(45) a. Context: When you were a child, you thought that Reno was a really big city. But since then, you've visited Sacramento and San Francisco, which are both much bigger, so you now know that Reno isn't that big after all.

b. dimé:huya? lí:nu t'íyeli? k'éPuyila? dihámuyujili

di-me:hu-a? li:nu t'izyeli? k'-e?-unil-a? di-hamu-unil-i

1-boy-DEP Reno big 3-COP-PAST-DEP 1-think-PAST-IND

'When I was a boy, I thought Reno was big.'

\#'When I was a boy, I thought Reno used to be big.'

Thus, - uyil behaves like the English past tense in both matrix and embedded environments. These facts would be surprising if -ujil was not a tense, but rather a temporal adverb, since temporal adverbs normally don't display these sorts of effects.

For completeness, I briefly describe the readings available for a morphologically tenseless clause embedded under a propositional attitude marked with -uyil, and for a clause marked with -ujil embedded under a morphologically tenseless attitude verb. In the first case, both a simultaneous reading and a back-shifted reading are available. In (46), two contexts are provided, one which favors the simultaneous reading, and one which favors the back-shifted reading. Speakers find the Washo form in (46b) acceptable in both contexts.

(46) a. Context A: You see a man in the street and say 'Hi Tim!' He tells you his name isn't Tim. You apologize, and say ...

Context B: You run into your old friend. His name used to be Tim, but you heard that he changed his name since you last saw him.

b. Tim degumdíPye? MéPa? dihámuyunili

Tim de-gum-di?ye? M-e?-a? di-hamu-unil-i

Tim NMLZ-REFL-name 2-COP-DEP 1-think-PAST-IND

Context A: 'I thought your name was Tim.' (simultaneous reading)

Context B: 'I thought your name used to be Tim.' (back-shifted reading)

By contrast, a verb marked with -unil embedded under a morphologically tenseless attitude verb only has a back-shifted reading. Using our now familiar mistaken identity context, speakers find the form in (47) unacceptable in the target context for the simultaneous reading.

(47) a. Context: You see a man in the street and say 'Hi Tim!' He tells you his name isn't Tim. You apologize, and say:

b. \# Tim degumdí?ye? MéPuyila? dihámuyi

Tim de-gum-di?ye? M-e?-unil-a? di-hamu-i

Tim NMLZ-REFL-name 2-COP-PAST-DEP 1-think-IND

Intended: 'I thought your name was Tim.'

Speaker comment: 'I thought your name used to be Tim.'

The fact that the simultaneous reading is unavailable can be exploited by speakers, who may choose this form to unambiguously signal that the back-shifted reading is the one intended. For instance, after presenting a speaker with the context in (48a), she volunteered the form in (48b). 
(48) a. Context: You were planning a trip, and your friends came over to say goodbye, but when they arrived, you had already left on the trip. When you get back ...

b. lé: gewík'ilunila? Tí:di lánala lí:

le: Ø-gewí:k'il-unil-a? P-ird-i le-ayal-a li:

1.PRO 3-look.for-PAST-DEP 3-say-IND 1.POSS-house-LOC PRT

léyowe?udiš

le-iye?-uwe?-ud-i-š

1-go-hence-SEQ-IND-SR

'They said they came to look for me, but I had already left.'

(time of looking-for $<$ time of saying)

In sum, the readings available for the different combinations of morphologically tenseless and tensed clauses under attitude verbs is summarized in (49). This summary is only for past interpretations of combinations of -unil-marked and morphologically tenseless clauses. A more detailed investigation of matrix and embedded clauses with other temporal reference combinations must await another occasion.

\begin{tabular}{|c|c|c|}
\hline & Simultaneous & Back-shifted \\
\hline past-under-past & $\checkmark$ & $\checkmark$ \\
\hline bare-under-past & $\checkmark$ & $\checkmark$ \\
\hline bare-under-bare & $\checkmark$ & $\checkmark$ \\
\hline past-under-bare & $\#$ & $\checkmark$ \\
\hline
\end{tabular}

\section{Analysis}

In this section, I formulate my analysis of -uyil as a past tense, and of morphologically tenseless clauses, couched within the pronominal/referential theory of tense (Abusch 1997; Heim 1994; Kratzer 1998; Partee 1973) as outlined in Sect. 1.3. While I focus mostly on past interpretations, I also provide an analysis for the cases where morphologically tenseless clauses can receive a future interpretation. I also compare my analysis with two alternatives, which I both reject. We begin with the simplest case, the analysis of -uyil.

\subsection{Analysis of -unil}

I propose that -ujil receives the same interpretation as English past tense. It places a presupposition that the identity of the temporal pronoun (given by the assignment function $g$ ) is before the utterance time $t_{c}$. We will begin with matrix clauses. The syntactic structure I assume for (3) is given in (50).

$$
\begin{aligned}
& \text { a. } \emptyset \text {-háPaš-uyil-i } \\
& \text { 3-rain-PAST-IND }
\end{aligned}
$$


b.

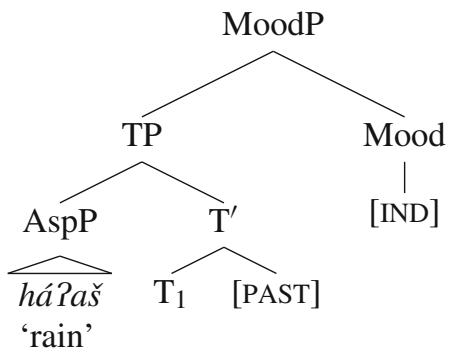

The sister to $\mathrm{T}^{\prime}$, labeled here as AspP, denotes a predicate of times. ${ }^{22}$ The temporal pronoun generated as the head of $\mathrm{T}$ saturates the time argument, deriving a proposition that is true if it rains in $w$ at time $g(1)$, with the added presupposition that $g(1)$ is located prior to utterance time. This semantic derivation is provided in (51), ignoring the contribution of mood morphology.
a. $\llbracket[A s p P h a P a \check{s}] \rrbracket^{g, c}=\lambda t \lambda w \cdot \operatorname{rain}(t)(w)$
b. $\llbracket \mathrm{T}_{1} \rrbracket^{g, c}=g(1)$
c. $\llbracket \mathrm{PAST} \rrbracket^{g, c}=\lambda t: t<t_{c} \cdot t$
d. 【[TP $[$ AspP $h a P a \check{s}]\left[\mathrm{T}_{1}\right.$ PAST $\left.\left.]\right] \rrbracket^{g, c}=\lambda w \cdot \operatorname{rain}(g(1))(w)\right)$ defined only if $g(1)<t_{c}$

This analysis captures the co-occurrence patterns with temporal frame adverbials in (33)-(35). Assuming that temporal adverbials also place constraints on the identity of the reference time, as in (52), it is clear why a verb marked with -ugil is only compatible with past-oriented adverbs.
a. $\llbracket w a t l i \rrbracket^{w, g, c}=\lambda t . t \subseteq$ this.morning
b. $\llbracket$ wá:din $\rrbracket^{w, g, c}=\lambda t . t \subseteq$ now
c. $\llbracket w a ́ t ~ \rrbracket^{w, g, c}=\lambda t . t \subseteq$ tomorrow

In the case of watli: 'this morning', the constraint placed of the reference time does not conflict with the presupposition of -unil, and so is acceptable. However, the constraints placed by wá:diy 'now' and wát 'tomorrow' conflict with the presupposition of -unil, resulting in a contradiction. This is made explicit in (53)-(55), where (53) with no contradiction is acceptable, while (54) and (55) contain contradictions (underlined), and are judged unacceptable.

a. watlí: wánawuyili

watli: w-anaw-unil-i

morning STATIC-good-PAST-IND

'It (the weather) was nice this morning.'

\footnotetext{
22 Even though aspect is not obligatory, I assume that AspP is below the T projection, following standard assumptions (e.g., Kratzer 1998). Nothing hinges on this choice of label though.
} 


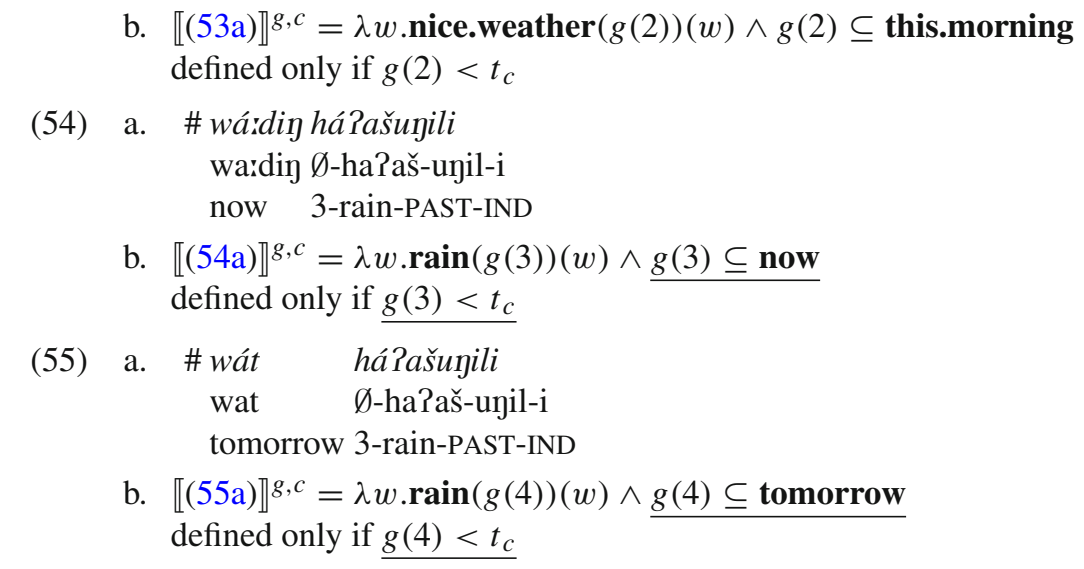

Recall from Sect. 3 that under attitude verbs, the embedded clause can receive either a "back-shifted" or "simultaneous" reading relative to the matrix clause. Since this observation is also found for the past tense in English under attitude verbs, I will simply borrow aspects of various analyses developed for English. In doing so, I do not wish to take a stand here on the correct way to derive these effects for English; rather, my goal is to present an analysis that is able to handle the data while being consistent with the main claims of this paper.

Let us begin with the "simultaneous" reading, as in (43) and (45). In this case, the emprical effect to be accounted for is that the embedded-ujil seems to have no contribution, in the sense that it does not induce a further backward shift in time. Rather, the time of the embedded clause is bound to that of the matrix clause.

I follow the general idea widespread in the literature that in these cases, there is simply no semantic tense in the embedded clause, despite the presence of the past tense morphologically. There are various technical means for implementing this idea, including tense deletion under identity with a c-commanding tense (e.g., Ogihara 1989), positing a "zero" past tense in the embedded clause (e.g., Heim 1994), or non-local licensing of past tense morphology (e.g., Kusumoto 2005; Stowell 2007).

Whatever the right way of doing this is, the structure and semantics for the simultaneous reading in (43) should look something like (56), again ignoring mood. There is only one PAST feature in the structure, namely the one in the matrix clause. There is no semantic past tense in the embedded clause, and the temporal variable is abstracted over to deliver a predicate of times as the complement of the attitude verb, and the time of the embedded clause is bound to the attitude time (the attitude-holder's now, $\left.t^{\prime}\right)^{23}$

${ }^{23}$ I use the variables $s p$ and $a d d$ to refer to the speaker and addressee, respectively. 
(56) a

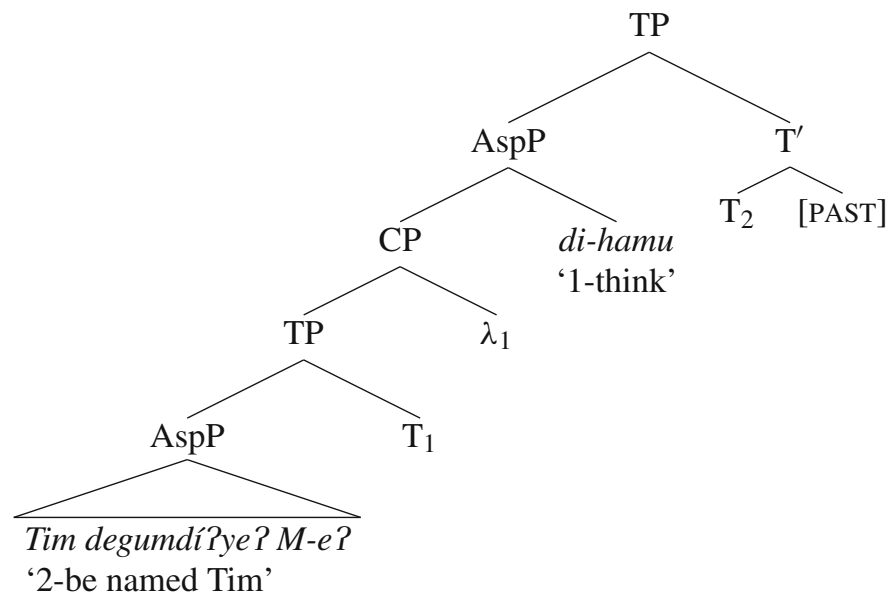

b. $\quad$ i. $\llbracket \mathrm{CP} \rrbracket^{g, c}=\lambda t_{1} \lambda w$.name $(t i m)(a d d)\left(t_{1}\right)(w)$

ii. $\llbracket h a m u \rrbracket^{g, c}=\lambda P\langle i,\langle s, t\rangle\rangle \lambda x \lambda t \lambda w . \forall\left\langle w^{\prime}, t^{\prime}\right\rangle \in \operatorname{Dox}_{x}(t)(w) \rightarrow P\left(t^{\prime}\right)\left(w^{\prime}\right)$

iii. $\llbracket(56 \mathrm{a}) \rrbracket^{g, c}=\lambda w \cdot \forall\left\langle w^{\prime}, t^{\prime}\right\rangle \in \operatorname{Dox}_{s p}(g(2))(w) \rightarrow \operatorname{name}($ tim $)($ add $)$ $\left(t^{\prime}\right)\left(w^{\prime}\right)$

defined only if $g(2)<t_{c}$

To obtain the "back-shifted" reading, as in (44), I follow Abusch (1997) and Heim (1994) in positing res-movement of the temporal pronoun and its tense feature. The key ingredients of the analysis are as follows. First, there is movement of the past tense of the embedded clause to the matrix clause, so that it is not interpreted under the scope of the attitude verb. Second, the context must provide a temporal acquaintance relation, $R$, such that the attitude holder bears $R$ to the lower past time in $w$ at $t$. The content of $R$ is essentially a description by which the attitude holder represents a time to herself. This is necessary for the temporal de re interpretation of the back-shifted reading. Third, we posit the Upper Limit Constraint, which prevents the lower tense from denoting a time after the eventuality time of the higher clause. ${ }^{24}$

For reasons of space, I won't go through a compositional analysis here. A sample LF for the back-shifted reading in (44) is given in (57a), where the res-moved tense and its trace are underlined. The truth conditions are given in (57b).

a. [ [ [ [ Tim gedumdíPye? M-e $\left.\left.{ }_{\mathrm{AspP}}\right] \underline{\mathrm{t}_{1}} \mathrm{TP}\right] \underline{\left[\mathrm{T}_{1} \mathrm{PAST}\right]}$ di-hamu $\left.\mathrm{AspP}\right]\left[\mathrm{T}_{2}\right.$ PAST ] TP]

b. $\llbracket(57 \mathrm{a}) \rrbracket^{g, c}=\lambda w \cdot \forall\left\langle w^{\prime}, t^{\prime}\right\rangle \in \operatorname{Dox}_{s p}(g(2))(w) \rightarrow \operatorname{name}(t i m)(\operatorname{add})(g(1))$ $\left(w^{\prime}\right)$

defined only if:

i. $g(1)<t_{c}$ and $g(2)<t_{c}$

(past tense presupposition)

\footnotetext{
${ }^{24}$ Additionally, we need to define a new "relational" version of hamu 'think' that takes the moved tense as an additional argument. I refer readers to Abusch (1997) and Heim (1994) for the technical details.
} 
ii. $g(1) \leq g(2) \quad$ (Upper Limit Constraint $)^{25}$

iii. $\quad c$ provides $R$ such that $R(g(1))(s p)\left(t^{\prime}\right)\left(w^{\prime}\right)=1 \quad$ (acquaintance relation)

In sum, borrowing fairly standard assumptions about the semantics of the past tense in English allows us to give a satisfactory analysis of matrix and propositional attitude complements containing -ujil. ${ }^{26}$ The remarkable similarities between -uyil in Washo and the past tense in English can thus be captured by giving them the same analysis. I now turn to the analysis of morphologically tenseless clauses.

\subsection{Analysis of morphologically tenseless clauses}

For morphologically tenseless clauses, I propose the same structure and semantics as clauses with -uyil for all the relevant pieces, except that there is no tense feature restricting the reference of the temporal pronoun. The syntax and semantics of (2) is thus given in (58)-(59).

\section{a. Ø-há?aš-i \\ 3-rain-IND}

b.

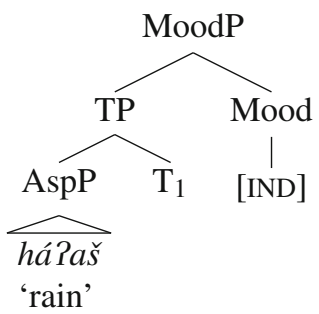

(59)
a. $\llbracket[A s p P h a ? a \check{s}] \rrbracket^{g, c}=\lambda t \lambda w \cdot \operatorname{rain}(t)(w)$
b. $\llbracket \mathrm{T}_{1} \rrbracket^{g, c}=g(1)$
c. $\llbracket\left[T P[\right.$ AspP $\left.h a ? a \check{s}] \mathrm{T}_{1}\right] \rrbracket^{g, c}=\lambda w \cdot \operatorname{rain}(g(1))(w)$

Since there is no presupposition placed on the value of the temporal pronoun, the analysis predicts that morphologically tenseless clauses are in principle compatible with past, present, or future time reference. We have seen that this is indeed the case, with several examples of each in Sect. 2. For concreteness, the analysis for (6) and (7) is given in (60)-(61), where the temporal adverbs wá:din 'now' and watlí: 'this morning' are compatible with morphologically tenseless clauses. Thus, in these cases, the identity of the reference time is only restricted semantically by the temporal adverbs themselves, and not a semantic tense.

\footnotetext{
25 This is not quite the correct presupposition that the Upper Limit Constraint imposes. Technically, the Upper Limit Constraint imposes a constraint on time concept functions $f$, whose output must be a time that is not later than the attitude holder's 'now'. See Heim (1994) for discussion.

${ }^{26}$ Combinations of morphologically tensed and tenseless clauses with propositional attitude predicates and complements will be discussed in Sect. 4.2.4.
} 
(60) a. wá:din wayák’aši

wa:din w-yak'aš-i

now STATIC-warm-IND

'It (the weather) is warm now.'

b. $\llbracket(60 a) \rrbracket^{g, c}=\lambda w \cdot \operatorname{warm}(g(2))(w) \wedge g(2) \subseteq$ now

(61) a. watlí: zírgìn lébikhayi

watli: zirgin le-ibik'-ha-i

morning chicken 1-be.cooked-CAUS-IND

'I cooked chicken this morning.'

b. $\llbracket(61 \mathrm{a}) \rrbracket^{g, c}=\lambda w \cdot \operatorname{cook}(c h)(s p)(g(3))(w) \wedge g(3) \subseteq$ this.morning

However, the analysis also predicts that future-oriented adverbs should also be possible with morphologically tenseless clauses, contrary to fact. Under my analysis, the semantics of (17) comes out as in (62), assuming an analysis of wá:din dewp'áwit 'tonight' parallel to (52), which does not explain why the sentence is judged as unacceptable.
a. \# wá:din dewp’áwit há?aši
wa:din dewp' awìd Ø-ha?aš-i
today evening 3-rain-IND
Intended: 'It will rain tonight.'
b. $\llbracket(62 \mathrm{a}) \rrbracket^{g, c}=\lambda w \cdot \operatorname{rain}(g(4))(w) \wedge g(4) \subseteq$ tonight

The challenge of this analysis is how to rule out future time reference more generally, which is only available in certain environments. A similar situation obtains for Paraguayan Guaraní (Tonhauser 2011), where future time reference of morphologically tenseless clauses is restricted, though not systematically absent.

Following Tonhauser (2011) for Paraguayan Guaraní, I propose that future reference times in Washo are in general not available. That is, in a case like (62), there is no suitable referent available for $g(4)$, since it is in the future of the utterance time. My idea is roughly the following: in a branching times model of temporal and modal reference (Thomason 1970, 1984), the past and future are asymmetrical, in the sense that the past is settled, while the future is not. I contend that this asymmetry is significant for the availability of reference times for morphologically tenseless clauses in Washo. Specifically, only reference times on the subsets of histories that are already settled can be referred to in morphologically tenseless clauses.

Nevertheless, we do find that morphologically tenseless clauses can sometimes receive absolute future reference. Such cases include examples like (19) where a plan for the future is at issue, cases like (22) where a clausal conjunction with the sequential morpheme - $u d$ licenses a future interpretation, and in conditional antecedents as in (30)-(32). My proposal is that future interpretations are available in planning contexts and conditionals due to the presence of a silent modal operator, and in conjunctions with - $u d$ because a reference time is asserted to exist, rather than being referred to. In the remainder of this sub-section, I discuss each of these cases in turn, and then I discuss the interpretation of relative clauses and complement clauses. 


\subsubsection{Unembedded future interpretations and plans}

In certain cases like (19) and (20), the latter repeated in (63) below, we find that future time reference of a morphologically tenseless clause is possible.

(63) a. Context: You want to know what Mona will cook for dinner later today.

b. hut'ayahé:š mó:na Pí:bikhayi dewp'áwit démlulewe hut'aya-herš mona ?-i:bik'-ha-i dewp'awid d-emlu-lewe what-Q Mona 3-be.cooked-CAUS-IND evening D.POSS-eat-for 'What will Mona prepare for dinner?'

In this context, there is a plan for what Mona will cook later on after the utterance time. I argue that this is crucial for the licensing of the future reading of the morphologically unmarked future interpretation of such sentences.

To implement this idea, I borrow the metaphysical modal operator PLAN of Copley (2002, 2008) and Thomas (2015), which is designed to account for futurate readings of present tense sentences in English, such as (64).

(64) The Red Sox play the Yankees tomorrow.

Copley argues that such futurate readings involve both a presupposition and an assertion regarding a director $d$ towards a proposition $p$. The presupposition is that $d$ directs $p$ in a world $w$ at time $t$, while the assertion is that $d$ is committed to $p$ in $w$ at $t$. Informally, what it means for $d$ to direct $p$ is that $d$ has the ability to bring about that $p$, and that $d$ is committed to bring about that $p$. The director $d$ is committed to $p$ in $w$ at $t$ if in all the best worlds metaphysically accessible from $w$ according to $d$ 's desires in $w$, there is a time $t^{\prime}$ in the future of $t$ where $p$ is true. So for (64), we can take Major League Baseball (or its executives) to be the entity directing the proposition that the Red Sox play the Yankees tomorrow, and committed to bring about that the Red Sox play the Yankees tomorrow.

The meaning contributions of PLAN can then be modeled as a modifier of a predicate of times $P$ in (65), where BEST (Portner 1998) picks out the best worlds of the modal base $\mathrm{MB}$ according to the bouletic ordering source $\mathrm{OS}_{d}$, here relativized to the director $d$ 's desires in $w$ at $t$.

$$
\begin{aligned}
\llbracket \mathrm{PLAN} \rrbracket^{g, c}= & \lambda P_{\langle i,\langle s, t\rangle\rangle} \lambda t \lambda w \cdot \forall w^{\prime}\left[w^{\prime} \in \mathrm{BEST}\left(\mathrm{MB}, \mathrm{OB}_{d}, t, w\right)\right] \rightarrow \exists t^{\prime}\left[t^{\prime}>t \wedge\right. \\
& \left.P\left(t^{\prime}\right)\left(w^{\prime}\right)\right] ; \\
& \text { defined only if } d \text { directs } P \text { in } w \text { at } t
\end{aligned}
$$

For the analysis of (19) and (63), I propose that PLAN applies to the embedded AspP, returning a predicate of times, where the time argument is then saturated by a temporal pronoun denoting the utterance time. That is, (19) has present temporal reference, but is future-oriented because PLAN introduces a time $t^{\prime}$ in the future of $g(1)$. The final semantics for B's response in (19) is then given in (66).

$$
\begin{aligned}
\llbracket(19 \mathrm{~B}) \rrbracket^{g, c}= & \lambda w \cdot \forall w^{\prime}\left[w^{\prime} \in \operatorname{BEST}\left(\mathrm{MB}, \mathrm{OB}_{d}, g(1), w\right)\right] \rightarrow \exists t^{\prime}\left[t^{\prime}>g(1) \wedge\right. \\
& \text { make } \left.(\operatorname{soup})(\operatorname{sp})\left(t^{\prime}\right)\left(w^{\prime}\right)\right] \\
& \text { defined only if } d \text { directs } \lambda t^{\prime} \lambda w^{\prime} \cdot \operatorname{make}(\operatorname{soup})(\operatorname{sp})\left(t^{\prime}\right)\left(w^{\prime}\right) \text { in } w \\
& \text { at } g(1)
\end{aligned}
$$


The analysis correctly predicts that cases like (62a) should be unacceptable due to presupposition failure. Specifically, the presupposition that there is a director $d$ that has the ability to bring it about that it rains in the future is not satisfied.

\subsubsection{Conditional antecedents}

Recall that not only can morphologically tenseless clauses in conditional antecedents have absolute future time reference, as in (30)-(31), but their reference time can also be in the future of the consequent time, as in (32), repeated here as (67).

(67) a. Context: Herman is expecting his cousin to come some time this week, but you don't know exactly when. But if his cousin is going to arrive tomorrow, then Herman must be happy now.

b. wát Herman Píryelu? Píbißiš wá:din

wat Herman 2 -i:yelu? 2 -i:bi?-i-š wa:din

tomorrow Herman 3-cousin 3-come-IND-SR now

hamu?ánawigi k'é?i

$\emptyset$-hamu-Payaw-i-gi k'-e?-i

3-feel-good-IND-SUBJ.REL 3-MOD-IND

'If Herman's cousin comes tomorrow, he is happy now.'

Since this observation is similar to the one described by Tonhauser (2011) for Paraguayan Guaraní, I adopt her analysis of conditionals, whereby they explicitly assert the existence of times, which can be either in the past, present, or future of the utterance time. ${ }^{27}$ I assume a conditional operator COND with the semantics in (68). It ensures that the antecedent $P$ is interpreted at worlds $w^{\prime}$ that are best according to an epistemic modal base MB and a stereotypical ordering source OS at a world $w$ and time $t$, which I take to be standard assumptions for conditionals (Kratzer 1986, 2012). COND furthermore asserts the existence of a time $t^{\prime}$ at which $P$ is interpreted, which can be a past, present, or future time. The truth conditions for (67) are then given in (69).

$$
\begin{aligned}
& \llbracket \mathrm{COND} \rrbracket^{g, c}=\lambda P_{\langle i,\langle s, t\rangle\rangle} \lambda Q_{\langle i,\langle s, t\rangle\rangle} \lambda t \lambda w . \forall w^{\prime}\left[w^{\prime} \in \operatorname{BEST}(\mathrm{MB}, \mathrm{OS}, t, w) \wedge \exists t^{\prime}\right. \\
& \left.\left[P\left(t^{\prime}\right)\left(w^{\prime}\right)\right]\right] \rightarrow \exists t^{\prime \prime}\left[Q\left(t^{\prime \prime}\right)\left(w^{\prime}\right)\right] \\
& \llbracket(67) \rrbracket^{g, c}=\lambda t \lambda w . \forall w^{\prime}\left[w ^ { \prime } \in \operatorname { B E S T } ( \mathrm { MB } , \mathrm { OS } , t , w ) \wedge \exists t ^ { \prime } \left[\operatorname{come}(\text { cous })\left(t^{\prime}\right)\left(w^{\prime}\right) \wedge\right.\right. \\
& \left.t^{\prime} \subseteq \text { tomorrow }\right] \rightarrow \exists t^{\prime \prime}\left[\operatorname{happy}(h)\left(t^{\prime \prime}\right)\left(w^{\prime}\right) \wedge t^{\prime \prime}=\text { now] }\right]
\end{aligned}
$$

Nothing in the semantics of COND restricts the relation between $t^{\prime}$ and $t^{\prime \prime}$. In the case of (67), the temporal adverbs impose constraints on the values of $t^{\prime}$ and $t^{\prime \prime}$, and so here the antecedent time is in the future of the consequent time. The modal aspects of the conditional are sufficient to license a future interpretation of a morphologically tenseless clause.

\footnotetext{
27 In doing so, I abstract away from the compositional details of conditionals in Washo, which I leave to another occasion.
} 


\subsubsection{Sequential -ud}

Morphologically tenseless clauses can also receive a future interpretation in conjoined structures, such as (22), repeated here as (70).

(70) a. Context: Mother Bear is about to go out gathering food. She tells her children what to do when she is gone.

b. léyewe?udiš há:?dawíPši memdé:wi na?mí?min

le-iyewe?-ud-i-š ha:?da wi?-ši memderwi ja?min RED

1-go-SEQ-IND-SR there 3.PRO-DU deer child $\sim$ PL

Pumdó:bašhayudi lé: mimdác'awéwahayaš

?um-do:baš-ha-ud-i le: mi-Pumdac'awewe-ha-a?-š

2-burn-CAUS-SEQ-IND 1.PRO 2-pound.up.meat-CAUS-DEP-SR

'After I go, you'll burn those two deer children to death and then pound them up for me.'

(Bear and Deer story)

Recall that in such constructions, the sequential morpheme - $u d$ occurs in all nonfinal conjuncts to indicate forward narrative progression, similar to English '(and) then'. However, - $u d$ also occurs with the same forward progression meaning in conjoined clauses with past temporal reference, as in (23). Furthermore, as shown in (36) and (41), - $u d$ can co-occur with the past tense -unil. Therefore, $-u d$ must not contribute future time reference.

I propose a semantics for $-u d$ given in (71), whereby it asserts the existence of a time $t^{\prime}$ where $P$ is true, and introduces a temporal relation of precedence between $t^{\prime}$ and another time $t$, which is identified with the reference time of the following clause. The time $t^{\prime}$ can be a past or future time. ${ }^{28}$

$$
\llbracket-u d \rrbracket^{g, c}=\lambda P_{\langle i,\langle s, t\rangle\rangle} \lambda t \lambda w \cdot \exists t^{\prime}\left[P\left(t^{\prime}\right)(w) \wedge t^{\prime}<t\right]
$$

To keep things simple, I will exemplify how the analysis works with just two conjoined clauses, namely the last two clauses in (70). I assume the structure of a biclausal conjunction as in (72). Given that - $u d$ can co-occur with - unil, I assume that - $u d$ adjoins above TP, where the temporal variable in the clause is abstracted over to deliver a predicate of times as the first argument of $-u d$, as required by (71). The temporal variable in the second clause (the clause not marked with $-u d$ ) is also abstracted over, so that it can be identified with the open temporal variable of the - $u d$-marked clause by the conjunction operator CONJ in (73).

\footnotetext{
28 See also Toosarvandani (to appear) for a similar analysis of a highly similar sequential marker in Northern Paiute. A key difference is that the sequential in Northern Paiute alternates with an overt simultaneity marker, and Toosarvandani analyzes both as instantiations of the Thead in that language. Note that in both languages, the sequential morpheme can also occur on the final clause of a conjunction, see e.g. (48).
} 
(72)

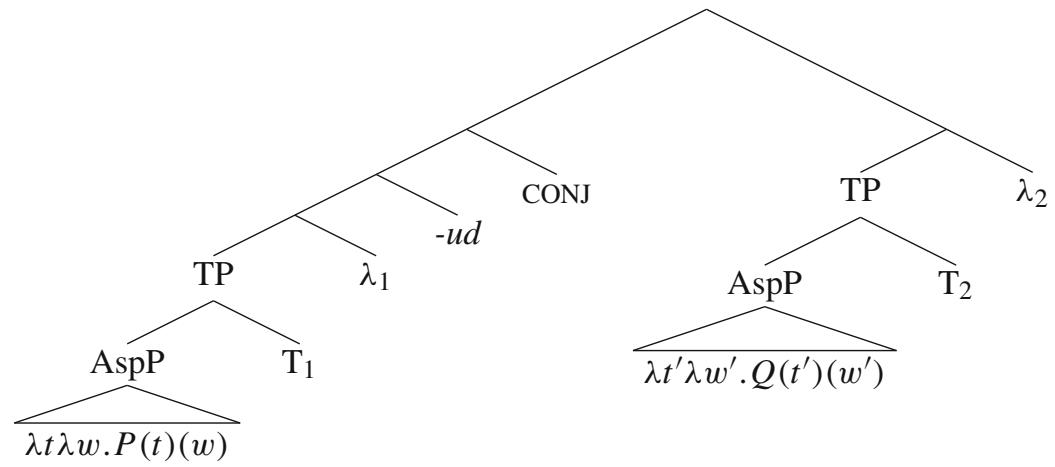

$$
\llbracket \mathrm{CONJ} \rrbracket^{g, c}=\lambda P_{\langle i,\langle s, t\rangle\rangle} \lambda Q_{\langle i,\langle s, t\rangle\rangle} \cdot \lambda t \lambda w \cdot P(t)(w) \wedge Q(t)(w)
$$

The meaning of - $u d$ applied to the predicate of times it embeds is given in (74). It returns a predicate of times $t$, which is true at $w$ if there exists a time $t^{\prime}$ such that the addressee burning the deer children to death is at $t^{\prime}$, and $t^{\prime}$ is before $t$. The truth conditions of the whole conjunction (i.e., the last two clauses in (70), and ignoring the causative 'for me' part of the second clause), are given in (75).

$$
\begin{gathered}
\llbracket-u d(P) \rrbracket^{g, c}=\lambda P \lambda t \lambda w . \exists t^{\prime}\left[P\left(t^{\prime}\right)(w) \wedge t^{\prime}<t\right]\left(\lambda t^{\prime} \lambda w^{\prime} \text {.burn.to.death }(\text { deer })\right. \\
\left.(\text { add })\left(t^{\prime}\right)\left(w^{\prime}\right)\right)=\lambda t \lambda w . \exists t^{\prime}\left[\text { burn.to.death }(\text { deer })(\text { add })\left(t^{\prime}\right)(w) \wedge t^{\prime}<t\right] \\
\llbracket \operatorname{CONJ}(-u d(P))(Q) \rrbracket^{g, c}=\lambda t \lambda w . \exists t^{\prime}\left[\text { burn.to.death }(\text { deer })(\text { add })\left(t^{\prime}\right)(w)\right. \\
\left.\wedge \operatorname{pound}(\text { deer })(\text { add })(t)(w) \wedge t^{\prime}<t\right]
\end{gathered}
$$

I assume that the final translation of the whole conjunction involves existential closure over an open temporal variable, as in (76). The idea is that the assertion of the existence of a time, together with the temporal precedence relation $t^{\prime}<t$, is enough to license an absolute future interpretation for a morphologically tenseless clause. This means that the morphologically tenseless clauses in (70) are predicted to be compatible with future temporal reference, and this prediction is upheld.

$$
\begin{aligned}
\llbracket(72) \rrbracket^{g, c}= & \lambda w \cdot \exists t \exists t^{\prime}\left[\text { burn.to.death }(\text { deer })(\text { add })\left(t^{\prime}\right)(w)\right. \\
& \left.\wedge \text { pound }(\text { deer })(\text { add })(t)(w) \wedge t^{\prime}<t\right]
\end{aligned}
$$

The truth conditions provided here for conjunctions with - $u d$ also predict that the conjoined clauses can have past temporal reference, and in particular are compatible with -uyil. This prediction is also upheld. For morphologically tenseless clauses, this is shown in the analysis of (77) given in (78). Meanwhile, the truth conditions for (79), which contains -uyil, are given in (80). The contribution of -uyil is the presupposition that $t^{\prime}$, the reference time of the clause containing-unil, be prior to the utterance time $t_{c}$, which is compatible with the proposed truth conditions for the conjunction containing $-u d .^{29}$

a. Context: You're telling me about yesterday's weather.

$\overline{29}$ I use $x$ and $y$ to represent the third person pronominal arguments in (80). 
b. háPašudi déPešgána?i

$\emptyset$-ha?aš-ud-i Ø-de?eš-gaya?-i

3-rain-SEQ-IND 3-snow-begin-IND

'It was raining, and then it began to snow.'

(79) a. Context: In the Spring, some Washos arrived at where the Donner Party had set up camp.

b. gesú:dumuпiludi ge-su:dum-unil-ud-i

\section{t’ánuma Pe?éssiš}

t'anu-ya 2 -e?-ess-i-šs

3.OBJ-look.for-PAST-SEQ-IND person-NC 3-COP-NEG-IND-SR

'They looked for them, but no one was there.' (Donner Expedition story)

$$
\begin{aligned}
\llbracket(79 \mathrm{~b}) \rrbracket^{g, c}= & \lambda w \cdot \exists t \exists t^{\prime}\left[\text { look.for }(x)(y)\left(t^{\prime}\right)(w) \wedge \neg \exists z[\text { be.there }(z)(t)(w)] \wedge t^{\prime}<t\right] \\
& \text { defined only if } t^{\prime}<t_{c}
\end{aligned}
$$

In sum, the constructions where future interpretations of morphologically tenseless clauses are available in Washo can be accounted for under my analysis. In all these cases, a modal operator and/or temporal precedence relation licenses future interpretations.

\subsubsection{Relative clauses and complement clauses}

Finally, I briefly discuss morphologically tenseless relative and complement clauses, and sketch their analysis. As observed in Sect. 2.3, morphologically tenseless relative clauses can receive either a back-shifted or simultaneous interpretation relative to the matrix eventuality time; see (24)-(25). I provide the proposed truth conditions for (25), repeated here as (81), in (82), setting aside a compositional analysis for reasons of space.

(81) a. Context: Mother Bear is searching for the deer who killed her children. She comes across a heron sitting by the river.

b. k’á:k'a? dá: gérgelišge yá:ma?

k'ark'a? da: Ø-gergel-i-š-ge Ø-ya:m-a?

heron there 3-sit-IND-SR-OBJ.REL 3-talk-DEP

'She spoke to a heron who was sitting there.'

(Bear and Deer story)

$\llbracket(81 b) \rrbracket^{g, c}=\lambda w \cdot \exists x[\operatorname{heron}(x) \wedge \operatorname{speak.to}(x)(y)(g(1))(w) \wedge \operatorname{sit}(x)(g(2))(w)]$

Since $(81 \mathrm{~b})$ is biclausal, there are two temporal pronouns in the structure. However, there are no tenses constraining the identities of $g(1)$ and $g(2)$ in (82), and nothing constraining the temporal relation between them. This analysis thus correctly predicts that relative clauses can in principle have a temporal interpretation that is either simultaneous or back-shifted relative to the matrix time. 
Recall also from Sect. 2.3 that morphologically tenseless clauses embedded under a morphologically tenseless attitude predicate can receive both "simultaneous" and "back-shifted" readings, just like tensed clauses. The analysis developed for -unilmarked clauses can thus be extended to these cases as well, minus the presuppositions of the past tense. For the simultaneous reading, as in (26)-(27), the temporal variable in the embedded clause is abstracted over and identified with the attitude holder's 'now' in the matrix clause, just like in (56). The only difference between cases like (26) and (56) is the additional presupposition in (56) that the time denoted by the temporal pronoun in the matrix clause be located before utterance time. Similarly, the analysis for the back-shifted interpretation of (28) parallels that for tensed clauses given in (57). Just like in (57), the embedded temporal pronoun undergoes res-movement so that it is not interpreted under the scope of the attitude verb. We must likewise assume the Upper Limit Constraint and a temporal acquaintance relation for these cases as well; only the additional past tense presupposition is absent in (28).

This analysis can also handle the 'mix-and-match' cases, where a tenseless clause is embedded under a tensed clause, and a tensed clause is embedded under a tenseless clause; see (49) for a summary of the possibilities. In the former case, both simultaneous and back-shifted readings are possible. As before, the embedded temporal pronoun can either be abstracted over, or undergo res-movement to obtain the desired readings. The latter case is interesting, since here the simultaneous interpretation is unavailable. For the back-shifted reading, we need res-movement, as before. However, to obtain the simultaneous reading for tensed embedded clauses, we needed to say that semantically there is no tense in the embedded clause. But this does not seem possible when a morphologically tensed clause is embedded under a morphologically tenseless attitude predicate - the downstairs tense must be interpreted. This appears to be evidence in favor of a deletion-based account of embedded tense (e.g., Ogihara 1989), whereby an embedded tense may be optionally deleted under identity with a matrix tense to obtain the simultaneous reading. That is, in a case like (56), the deletion of the embedded past tense is licensed by the presence of the upstairs past tense. In cases like (47), however, there is no upstairs tense to license such a deletion, and so the downstairs tense must be interpreted, and no simultaneous reading is available.

\subsection{Alternative analyses for morphologically tenseless clauses}

\subsubsection{Null non-future tense}

In this subsection, I explore and reject two alternative analyses for morphologically tenseless clauses that appear to have some initial plausibility. The first would be to say that morphologically tenseless clauses do contain a tense after all, just a phonologically silent one, following Matthewson (2006) for St'át'imcets. Under Matthewson's analysis, a covert tense morpheme restricts the value of a temporal pronoun in morphologically tenseless clauses (or what she calls "superficially" tenseless clauses). This morpheme, defined in (83), appears in all finite clauses, and restricts the value of 
the temporal pronoun to non-future intervals. The syntax and semantics of (2) would then be as in (84)-(85). ${ }^{30}$

(83) $\llbracket$ NONFUT $\rrbracket^{g, c}=\lambda t . t$; defined only if no part of $t$ is after $t_{c}$ (adapted from Matthewson 2006, p. 680)
a. Ø-háPaš-i
3-rain-IND

b.

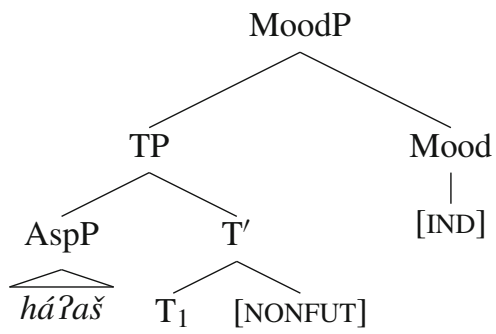

(85)

$\llbracket \mathrm{TP} \rrbracket^{g, c}=\lambda w \cdot \operatorname{rain}(g(1))(w)$

defined only if no part of $g(1)$ is after $t_{c}$

A major empirical advantage of this analysis is that it predicts the co-occurrence restrictions with temporal adverbs that were problematic above, without the additional assumption that future reference times are unavailable. Specifically, (17) would be analyzed as in (86), where the contradiction between the presupposition of NONFUT and the semantics of the future-oriented adverb explains why the sentence is judged unacceptable.

a. \# wá:din dewp'áwit háPaši

wa:din dewp' awìd Ø-ha?aš-i

today evening 3-rain-IND

Intended: 'It will rain tonight.'

b. $\llbracket(86 a) \rrbracket^{g, c}=\lambda w \cdot \operatorname{rain}(g(2))(w) \wedge g(2) \subseteq$ tonight defined only if no part of $g(2)$ is after $t_{c}$

This analysis can also handle cases of absolute future time reference in planning contexts such as (19) and (63), also by appealing to the PLAN operator as before. I argued that such cases in fact involve present temporal reference with a future time introduced by PLAN. Thus, adding the presupposition that no part of $g(1)$ be located after $t_{c}$ as in (87) still predicts futurate readings to be possible in planning contexts such as (19B).

\footnotetext{
${ }^{30}$ An analysis along these lines is pursued by Cable (2016) for optional past tense ("decessive") in Tlingit. Under such an analysis, the question of what it means for tenses to be optional becomes moot. The question is no longer relevant because there $i s$ a paradigm of tenses, PAST and NONFUT, the latter of which happens to be unpronounced, and occurs in finite clauses wherever PAST does not. This point will become relevant in Sect. 5, where presuppositional alternatives will be at issue.
} 
(87) a. [ [ [ šú:pk'éy lí: di-do:da? AspP] PLAN ] [ $\mathrm{T}_{1}$ NONFUT $\left.\left._{\mathrm{T}^{\prime}}\right] \mathrm{TP}\right]$

b. $\llbracket(19 \mathrm{~B}) \rrbracket^{g, c}=\lambda w \cdot \forall w^{\prime}\left[w^{\prime} \in \operatorname{BEST}\left(\mathrm{MB}, \mathrm{OB}_{d}, g(1), w\right)\right] \rightarrow \exists t^{\prime}\left[t^{\prime}>g(1) \wedge\right.$ make $\left.(\operatorname{soup})(s p)\left(t^{\prime}\right)\left(w^{\prime}\right)\right]$

defined only if $d$ directs $\lambda t^{\prime} \lambda w^{\prime}$.make $(\operatorname{soup})(\operatorname{sp})\left(t^{\prime}\right)\left(w^{\prime}\right)$ in $w$ at $g(1)$,

and no part of $g(1)$ is after $t_{c}$

On the face of it, this analysis appears to have difficulty in other cases where future temporal reference is possible in morphologically tenseless clauses, such as in conditional antecedents, and conjunctions with - $u d$. First, it was observed that conditional antecedents not only can receive absolute future reference, but also that the time of the antecedent can be in the future of the time of the consequent. The analysis with NONFUT tense seems to make the wrong prediction in this case. Even if we assume that NONFUT is a relative tense where the evaluation time can be shifted to the consequent time, the analysis in (88) for (67) would still predict that the antecedent time must be in the non-future of the consequent time. Moreover, in the case of (67) where the consequent time overlaps with utterance time, the presupposition of NONFUT in the antecedent clause contradicts the contribution of the temporal adverb, and so (67) is predicted to be unacceptable, contrary to fact.

$$
\begin{aligned}
\llbracket(67) \rrbracket^{g, c}= & \lambda t \lambda w . \forall w^{\prime}\left[w ^ { \prime } \in \operatorname { B E S T } ( \operatorname { M B } , \mathrm { OS } , t , w ) \wedge \exists t ^ { \prime } \left[\operatorname{come}(\text { cous })\left(t^{\prime}\right)\left(w^{\prime}\right) \wedge\right.\right. \\
& \underline{\left.t^{\prime} \subseteq \text { tomorrow }\right] \rightarrow \exists t^{\prime \prime}\left[\mathbf{h a p p y}(h)\left(t^{\prime \prime}\right)\left(w^{\prime}\right) \wedge t^{\prime \prime}=\mathbf{n o w}\right]} \\
& \text { defined only if no part of } t^{\prime \prime} \text { and no part of } t^{\prime} \text { is after } t_{c}
\end{aligned}
$$

However, caution is warranted in interpreting the results here. While it is indeed the case that the tensed analysis considered here cannot straightforwardly deal with the facts, there remain difficult issues regarding tense in conditionals, even for well-studied languages like English. Consider (89), from Kaufmann (2005, p. 268).

(89) If I come out smiling, the interview went well.

In (89), the consequent clause contains a past tense, but is interpreted in the future of the utterance time. The antecedent clause contains a present tense, but is interpreted in the future of consequent time. Note that this example cannot be saved by positing a PLAN operator in the antecedent clause. The conditional does not have the reading 'If it is planned that I come out smiling. . ' . The point of bringing up this example is to highlight that the modality of conditionals can influence the interpretation of tenses in sometimes unexpected ways. Therefore, it is far from clear that temporal interpretation in conditionals should serve as a litmus test for deciding between the tensed and tenseless analysis for morphologically tenseless clauses, in Washo and across languages.

Second, we observed that conjunctions with - $u d$ allow absolute future time reference. If we carry over the analysis of - $u d$ from Sect. 4.2.3, together with the assumption that NONFUT appears in every finite morphologically tenseless clause, the analysis of $(22) /(70)$ is the same as before, but with the additional presuppositions that no part of the temporal variables in either clause can be located after $t_{c}$, as shown in (90). ${ }^{31}$

31 Again, we restrict ourselves to the final two clauses for simplicity. 
Thus, it is predicted that such clauses can only have non-future temporal reference, contrary to fact.

$$
\begin{aligned}
\llbracket(22) /(70) \rrbracket^{g, c}= & \lambda w \cdot \exists t \exists t^{\prime}\left[\text { burn.to.death }(\text { deer })(\text { add })\left(t^{\prime}\right)(w)\right. \\
& \left.\wedge \text { pound }(\text { deer })(\text { add })(t)(w) \wedge t^{\prime}<t\right] \\
& \text { defined only if no part of } t \text { and no part of } t^{\prime} \text { is after } t_{c}
\end{aligned}
$$

Let us now take stock. An analysis involving a null NONFUT tense in morphologically tenseless clauses can account for future planning contexts just as well as the tenseless analysis, and can provide an explanation for the temporal adverb co-occurrence facts. The NONFUT analysis appears to fail for conditionals, but I argued that conditionals are not the best place to look to distinguish the two theories. This leaves future interpretations with $-u d$, where the NONFUT analysis does in fact stumble. The restriction to non-future times is simply too strong in this case, and makes the wrong predictions. Thus, the range of extant data that empirically distinguish my analysis from the NONFUT analysis is in fact quite narrow. In Sect. 5, I will offer a new argument against the NONFUT analysis based on (the lack of) Maximize Presupposition effects. First though, I will compare my analysis with the truly tenseless analysis of Tonhauser (2011).

\subsubsection{No Thead in morphologically tenseless clauses}

Another possible analysis would be to claim that morphologically tenseless clauses completely lack a $\mathrm{T}$ node or temporal pronoun at all, following the analysis of Tonhauser (2011) for Paraguayan Guaraní. The syntax and semantics of (2) would then be as in (91)-(92). However, since (92) denotes a predicate of time, the additional Matrix Clause Rule in (93) needs to be invoked in order to deliver a proposition, where $t_{r t}$ is the reference time of the clause. The final translation of (2) is then given in (94).

a. Ø-há?ǎ̌-i

3-rain-IND

b.

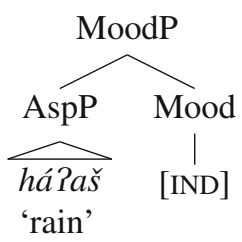

(92) $\llbracket \mathrm{AspP} \rrbracket^{g, c}=\lambda t \lambda w \cdot \operatorname{rain}(t)(w)$

(93) Matrix Clause Rule:

The final translation of a matrix clause translated as $\phi$ of type $\langle i,\langle s, t\rangle\rangle$ is $\phi\left(t_{r t}\right)\left(w_{c}\right)$ (adapted from Tonhauser 2011)

$$
\llbracket \operatorname{MoodP} \rrbracket^{g, c}=\operatorname{rain}\left(t_{r t}\right)\left(w_{c}\right)
$$

Under this analysis, there is no need to posit a temporal pronoun or T projection in morphologically tenseless clauses, which may be desirable given that there are no morphological reflexes of $\mathrm{T}$, and the value of the reference time is left unconstrained. 
Since the identity of the reference time under this account would still be identified through regular pragmatic/anaphoric principles (e.g., Bittner 2014), the predictions made by my analysis and Tonhauser's would be identical, at least for matrix clauses.

However, there are two reasons why my analysis is better suited to the Washo data. First, unlike Paraguayan Guaraní, Washo is not a tenseless language. That is, there is at least one morpheme in Washo that can be analyzed as a tense, namely -ujil, so we need to appeal to tense at least in some cases. It then becomes a question of whether a completely tenseless analysis (i.e., one lacking $\mathrm{T}$ at all) for morphologically tenseless clauses in Washo is overall more parsimonious than the one I am pursuing. I suggest that my analysis is actually more parsimonious overall than one that treats morphologically tensed and tenseless clauses as involving fundamentally different structures (i.e., structures with or without $\mathrm{T}$ and its projections). Second, the data from embedded contexts is different for Washo and Paraguayan Guaraní. Tonhauser shows that a back-shifted interpretation for tenseless clauses embedded under attitude predicates is not attested, and uses this fact as an argument against representing tense in embedded clauses, and for her analysis more generally. However, as we have already seen, this is not the case for Washo, since tenseless clauses embedded under attitude predicates can receive a back-shifted interpretation. This observation provides support for the idea that a temporal pronoun is represented syntactically in Washo. ${ }^{32}$ In the analysis sketched above in Sect. 4.2.4, the embedded temporal pronoun undergoes res-movement in order to derive the back-shifted reading. Although morphologically tenseless clauses in Washo and Paraguayan Guaraní pattern similarly in many key respects, the (un-)availability of back-shifted readings in embedded contexts constitutes an interesting point of variation between the two languages, which ultimately require different analyses.

\section{Presuppositional alternatives}

Recent work on presuppositions and blocking has seen increasing use of Maximize Presupposition (MP), a principle that requires that a sentence with the strongest presupposition be chosen amongst its alternatives (Heim 1991; Percus 2006; Schlenker 2012). A somewhat simplified version of MP is given in (95), adapted from Schlenker (2012).

\section{(95) Maximize Presupposition:}

If a sentence $S$ is a presuppositional alternative of a sentence $S^{\prime}$, and the context $C$ is such that
a. the presuppositions of $S$ and $S^{\prime}$ are satisfied within $C$
b. $S$ and $S^{\prime}$ have the same assertive component relative to $C$
c. $S$ carries a stronger presupposition than $S^{\prime}$
then $S$ should be preferred to $S^{\prime}$

\footnotetext{
32 Compare Mucha (2013) for similar facts in Hausa.
} 
Tensed and tenseless clauses in Washo fall under the criteria in (95), and so should be subject to MP. Let's illustrate with (3) as $S$ and (2) as $S^{\prime}$. Their semantic analyses are repeated below in (96) and (97), respectively.
a. Ø-há?ǎ̌-unil-i
3-rain-PAST-IND
b. $\lambda w \cdot \operatorname{rain}(g(1))(w)$
defined only if $g(1)<t_{c}$
a. Ø-há?ă̌-i
3-rain-IND
b. $\lambda w \cdot \operatorname{rain}(g(1))(w)$

$$
=S^{\prime}
$$

First, for a $C$ where $g(1)<t_{c}$, the presuppositions of both $S$ and $S^{\prime}$ are satisfied (vacuously for $S^{\prime}$ ). Second, both have the same asserted component: relative to a $C$ where $g(1)<t_{c}$, the asserted component for both $S$ and $S^{\prime}$ is that it rains in a world $w$ at time $g(1)$. Finally, the presupposition of $S$ is stronger than that of $S^{\prime}$, since $S^{\prime}$ does not carry any temporal presupposition. Thus, based on (95), $S$ and $S^{\prime}$ are the right sort of candidates to compete as alternatives, and so a clause containing -uyil should be preferred over a tenseless clause in any context where the presuppositions are met, i.e., whenever there is a topical past reference time in the context. Tenseless clauses, having a weaker presupposition, should then only be used when the presuppositions of -uyil are not satisfied, i.e., when the reference time includes a non-past time. Sauerland (2002) in fact capitalizes on exactly this prediction for his argument that the present tense in English is vacuous (i.e., carries no temporal presupposition), and only receives its non-past interpretation as an 'anti-presupposition' that it only be used when the presuppositions of the past tense are not satisfied.

However, the predictions are plainly wrong for the Washo facts, since tenseless clauses readily appear in contexts where the presuppositions of -unil are satisfied. This poses a problem for MP as stated in (95), since it seems to not apply. This is quite problematic, since, as argued by Schlenker (2012), MP can be derived from more general Gricean pragmatic principles, which are presumably universal, or at least should not be systematically absent in any given language.

The culprit, I suggest, is located in the if-clause of the statement of MP in (95). Since the application of MP is conditionalized on whether $S$ and $S^{\prime}$ are presuppositional alternatives, it must be the case that tensed and tenseless clauses in Washo are not the right kind of presuppositional alternatives that MP can apply to.

Typically, the presuppositions that are compared by MP are carried by lexical items that form a scale of strength. Some widely-discussed examples in the literature include $\{a, t h e\},\{a l l$, both $\}$, and $\{$ think, know $\}$, whereby the elements on the right of each pair carry stronger presuppositions than those on the left. In principle, one could propose a scale of $\{\varnothing$, PAST $\}$, where $\emptyset$ represents the absence of a lexical element rather than a null member of a paradigm. Since PAST carries a stronger presupposition, MP should apply, but this is exactly the prediction we wish to avoid to account for the Washo data. It seems then that a scale of the sort $\{\varnothing$, PAST $\}$ should be ruled out. I suggest that the reason this is so is because the resulting sentences to be compared by MP do not have an identical syntactic structure. In particular, the presence or absence of a 
tense feature is enough of a structural difference that the resulting sentences cannot be compared by MP, and do not trigger its application. In other words, the existence of a paradigm is crucial to generate the alternatives that enter into a MP competition.

In support of this view, note that whereas English $\{$ all, both $\}$ form an appropriate scale for MP, $\{\varnothing$, both $\}$ do not. Note the contrasts in (98)-(100), given that the current US President (Barack Obama at the time of writing) has exactly two children.

(98) \#All the US President's children were born in Illinois.

(99) Both the US President's children were born in Illinois.

(100) The US President's children were born in Illinois.

The MP-based analysis for the contrast between (98)-(99) holds that both must be used, since its presuppositions, which are stronger than those for all, are satisfied in the context. But a similar explanation cannot explain why both (99) and (100) are acceptable in the same context. The presuppositions of both sentences are satisfied in the context, and the presuppositions in (99) are stronger, yet (100) is not blocked. We seem to be in a situation just like the one for Washo tensed versus tenseless clauses. I suggest we can make sense of the data in a parallel way: (99) and (100) are simply not comparable, since (99) has extra structure that (100) lacks, even though their presuppositional asymmetry in principle would otherwise trigger MP. ${ }^{33}$ The relevant paradigm for the MP competition is $\{$ all, both $\}$, and sentences with the same asserted content but not containing a member of the paradigm do not form part of the alternative set.

The apparent puzzle regarding the non-application of MP can thus be understood when we narrow down the sorts of sentences that count as presuppositional alternatives in the first place. Crucially, the MP alternatives must be generated from a set of lexical items that form a paradigm, and in the case of the optional past tense in Washo, we have only a single-membered paradigm. Following Percus (2006), Singh (2011), and others, we must therefore add extra conditions to define the morphological items that generate the MP alternatives, to supplement the definition in (95). Crucially, as the optional tense data show, there must be a constraint that neither member of the scale be $\emptyset$, i.e., the absence of a morpheme. I formulate this idea in (101).

\section{(101) Paradigmatic Presuppositional Alternatives:}

If $\langle\alpha, \beta\rangle$ is a scale, where $\alpha, \beta \neq \emptyset$, and $S^{\prime}$ is a sentence containing $\alpha$, and $S$ is a sentence containing $\beta$ in the same terminal node where $S^{\prime}$ contains $\alpha$, then $S^{\prime}$ is a presuppositional alternative to $S$.

If this line of reasoning is correct, then the lack of MP effects serve as another argument against an analysis of morphologically tenseless clauses as containing a null NONFUT tense. Under such a scenario, the elements \{NONFUT, PAST $\}$ would form a paradigm of tenses. Alternatives generated by the paradigm would enter into an MP competition, since the presuppositions of PAST are a subset of the presuppositions of NONFUT. Then, by MP, sentences containing NONFUT should in most contexts carry

\footnotetext{
33 For this argument to go through, we must assume that (98)-(100) all have the same assertive component, which may be controversial. See Brisson (2003) and Lasersohn (1999) for analyses in which they do.
} 
the anti-presupposition that the PAST presupposition is not satisfied, i.e., it should effectively function as a present tense, which is the undesired prediction. Thus, the lack of MP effects serves as a novel argument against a null NONFUT in morphologically tenseless clauses in Washo, and potentially other languages as well. ${ }^{34}$

The idea that Maximize Presupposition should be relativized to morphological paradigms can help us understand the relation between morphological and semantic markedness. In the case of $\{\varnothing,-u j i l\}$, as well as $\{\varnothing$, both $\}$, we observe a symmetry between semantic markedness and morphological markedness. That is, the $\emptyset$ member of each pair represents both semantic vacuity and morphological vacuity, while the morphologically marked member is also the semantically marked member, i.e., has semantic import. This situation contrasts with the typical cases where MP is invoked. For instance, in the case of $\{a, t h e\}$, both members of the paradigm are equally morphologically marked, and each are semantically marked (Heim 1991). However, the carries a stronger presupposition, and wins out in an MP-based competition when its presuppositions are met. In the case of English present versus past tense, both members of the paradigm are morphologically marked. However, in Sauerland's (2002) analysis, only the past tense is semantically marked, while the present tense is semantically vacuous. ${ }^{35}$ In this case, MP applies, and the present tense only receives its apparent meaning as an anti-presupposition when the presupposition of the past tense is not satisfied. Meanwhile, in their analysis of the singular/plural contrast (in English), Sauerland et al. (2005) argue that the morphologically unmarked singular form is actually the semantically marked one, while the morphologically marked plural form is semantically unmarked. Once again, MP is invoked to explain the distribution of these forms. The singular is used whenever its presuppositions are met, while the plural is used in the elsewhere case, and acquires its apparent meaning as an antipresupposition. ${ }^{36}$ By contrast, in the case of $\{\varnothing$, -unil $\}$, morphological and semantic markedness align, and we find that MP does not apply. This is precisely the type of scale that (101) rules out.

These observations are summarized in (102).

\begin{tabular}{|l|c|c|c|}
\hline Forms & $\begin{array}{c}\text { Semantic } \\
\text { Markedness }\end{array}$ & $\begin{array}{c}\text { Morphological } \\
\text { Markedness }\end{array}$ & $\begin{array}{c}\text { MP } \\
\text { applies? }\end{array}$ \\
\hline$\{a$, the $\}$ & Both & Both & $\checkmark$ \\
\hline$\{$ PRESENT, PAST $\}$ (English) & One member only & Both & $\checkmark$ \\
\hline$\{$ SG, PL $\}$ (English) & One member only & Opposite member & $\checkmark$ \\
\hline$\{\emptyset,-$ uil $\},\{\emptyset$, both $\}$ & One member only & Same member & $*$ \\
\hline
\end{tabular}

What we can glean from this is that an MP competition does not apply when only one and the same member of the pair is both semantically and morphologically marked. In this case, then, there is a sense in which there is actually no pair to begin with, the

\footnotetext{
34 Note that Cable's (2016) analysis for Tlingit predicts that MP should require that past marking is used whenever its presuppositions are satisfied, since he posits a null NONFUT tense whenever the optional past tense is not used. Cable also posits a constraint on including as many topic times as possible within the denotation of the reference time pronoun, which may obviate the MP competition in certain contexts.

35 See Thomas (2015) for arguments against this view.

36 See Farkas and de Swart (2010) for arguments against this view, and an alternative analysis.
} 
members of which can be compared by MP. ${ }^{37}$ Perhaps it is not so surprising, then, that a constraint like MP does not apply in cases exactly like the optional past tense in Washo, or in cases with both the versus plain the in English. This case study thus reveals something about the nature of presuppositional alternatives and MP, specifically the range of its application in natural language.

\section{Cessation implicatures}

There are certain pieces of data that potentially cast doubt on my analysis of -uyil as simply a past tense, parallel to the past tense in English. As observed by Jacobsen (1964), -uyil seems to contribute more than just a past temporal reference, it also "indicates an interruption or cessation of the action or condition expressed by the theme to which it is affixed" (Jacobsen 1964, p. 607). He goes on to say that -unil "also commonly expresses a semantic linkage with the following verb, in cases where the action or condition expressed by the latter is not the normally expected sequel of the one expressed by the verb to which -uyil is affixed - cases where the first action is interrupted, thwarted, nullified, rejected, or counteracted by the second action" (Jacobsen 1964, p. 607).

In support of these claims, Jacobsen provides several examples where cessation readings seem to occur. For instance, (103) gives rise to a cessation of state reading according to Jacobsen. Namely, the state of being on the ground, marked with -uyil, comes to an end when the subject comes to his senses.
k’uléwe Puniludi
hámuguyúrgeti?a?
Ø-k'ule-iwe?-unil-ud-i
$\emptyset$-hamuguyu:g-eti?-a?

3-be.lying.down-direction-PAST-SEQ-IND 3-think.straight-INCH-DEP

'He lay on the ground, and then he came to his senses.' (Jacobsen 1964, p. 608)

For eventive predicates marked with -uyil, it is the result state of the event that ceases to hold. For instance in (104), the predicate táwini?gišuwe? 'go to town' is marked with -ujil, and as the following clauses indicate, the result state of being in town no longer holds. Meanwhile in (105), the result state of an eating event, i.e., that food has been ingested, no longer holds, given the following clause.

(104) ditáwini?gišuwe Punilišna wayásaniš

di-tawin-i?-giš-uwe?-unil-i-š-na w-yasay-i-š

1-town- ATTR-along-hence-PAST-IND-SR-but STATIC-hot-IND-SR

dipírgelay?legi

di-p'-irgel-a?y-leg-i

1-walk-turn.around-away-REC.PST-IND

'I went to town, but it was too hot, and I turned back.' (Jacobsen 1964, p. 609)

\footnotetext{
37 More precisely, the sentences containing them are not compared by MP.
} 


\section{(105) Pémluyunilige sesmáPyi \\ ?-emlu-unil-i-ge $\quad \emptyset$-sesm-a?y-i \\ 3-eat-PAST-IND- OBJ.REL 3-vomit-away-IND}

'He ate it and then he vomited it up.'

(Jacobsen 1964, p. 608)

Finally, (106)-(107) seem to give rise to what Jacobsen describes as an unexpected result reading. In (106), the expected result of jumping on someone who is asleep would be that they wake up, while in (107), one might reasonably expect someone to enjoy food that has been fed to them, though this characterization of (107) might be a bit tenuous here.

(106) míwi? malá:ya?éPešgayapgap’ilunilišgina

mi-wi? Ø-mele-ạa?e-i?iš-gayab-gap'ìl-unil-i-š-gi-ıa

2-3 3-jump-on-motion-over-around- PAST- IND- SR- SUBJ.REL-but

méPidaya mémc'iyérsaš

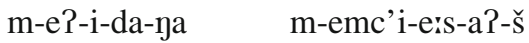

2-COP-IND-there-NC 2-wake.up-NEG-DEP-SR

'He kept jumping on you while going by, but where you were, you didn't wake up.'

(Jacobsen 1964, p. 609)

(107) gebúPuyuyilišgina

gala:méssa?

ge-bu?u-unil-i-š-gi-na Ø-galarm-e:s-a?

3.OBJ-feed-PAST-IND-SR-SUBJ.REL-but 3-like-NEG-DEP

'They fed it to him, but he didn't like it.'

(Jacobsen 1964, p. 608)

Interestingly, such inferences associated with optional past morphology are not unique to Washo. Cable (2016) notes that the Tlingit decessive (optional past tense) is described by Leer (1991) as having similar cessation and unexpected result implications. Moreover, Plungian and van der Auwera (2006) characterize languages with optional past tenses as giving rise to these implications when the past tense morpheme is present. For this reason, Plungian and van der Auwera claim that optional past tenses in these languages in fact conventionalize more than simply a meaning of past temporal reference. Rather, these languages have what they call 'discontinuous' pasts, which conventionalize a meaning of "past and not present", unlike languages like English, where past tense does not conventionalize anything specific about the present.

Cable (2016) shows that in Tlingit, the cessation inference is merely an implicature, and not part of the conventional content of the decessive. Evidence from Washo also suggests that the cessation interpretation of -uyil is an implicature. In contexts where cessation of a state is asserted, -uyil is not required, as shown in (108)-(109). In fact, in (109), one speaker actually showed a dispreference for marking the verb whose post-state no longer holds (marked here by ?).

(108) a. Context: You dropped a plate and it broke, but then you glued it back together.

b. c'iná:m digót'ahayi

Pudi

didó:da?i

c'ina:m di-got'a?-ha-i ?-ud-i

di-do:da?-i

plate 1-broken-CAUS-IND THEME- SEQ- IND 1-fix-IND

'I broke the plate, and then I fixed it.' 
(109) a. Context: You were sick, so you took some medicine, but it didn't really help.

b. múc'uk léme?(?-unil)udi hálana dihamu?ánawšemuyéssi

muc'uk le-ime?(-unil)-ud-i halaya di-hamu-?ayaw-šemu-ers-i

medicine 1-drink-PAST-SEQ-IND still 1-feel-good-really- NEG- IND

'I drank the medicine, but I still don't feel very good.'

Crucially, the cessation inference can be cancelled. In (110), the state of being hot is asserted to hold both in the past, and continuing into the present. Meanwhile in (111), it is asserted that the result state of arriving in Reno, i.e., being in Reno, still holds at utterance time.

(110) a. Context: We're discussing the very hot weather we've been having.

b. banáya wayásayšémuyunilina hálana wayásayšémuyi

bajaya w-yasan-šemu-unil-i-na halaja w-yasay-šemu-i

outside STATIC-hot-really-PAST-IND-but still STATIC-hot-really-IND

'It was hot outside before, and it's still really hot!'

(111) a. Context: You were planning to go to Reno, so I call you to see if you got there ok, and if you're still there.

b. lí:nuya lí: lébi?unilina hálana wá? léPi

li:nu-a li: le-ibi?-unil-i-na halaya wa? le-e?-i

Reno-LOC PRT 1-come-PAST-IND-but still there 1-be-IND

'I got to Reno, and I'm still there.'

The fact that the cessation inference is an implicature indicates that it is not part of the conventional content of -uyil. Thus, we can maintain an analysis where -uyil simply encodes past time reference, and any extra information that is apparently conveyed by - unil can be treated as an implicature. I leave the exact characterization and analysis of the implicature for future research, though see Cable (2016) on deriving the cessation and unexpected result implicatures for the decessive in Tlingit. Of particular interest would be to test embedded uses of -uyil and what types of inferences are available (or not) in embedded contexts.

\section{Further issues in past temporal reference in Washo}

There remain several open issues related to past temporal reference in Washo that are still in need of further research. One major issue that I have abstracted away from in this paper is that in addition to -uyil, Washo additionally possesses a series of "graded tenses", also known as temporal remoteness morphemes following Cable (2013). These morphemes are also verbal suffixes, and indicate the degree of remoteness between the speech time and the event named by the verb phrase. There are three past temporal remoteness morphemes described by Jacobsen (1964), shown in (112)-(114): -leg 'recent past', -ay? 'intermediate past', and -lul 'distant past'. 
(112) háPašlegi

$\emptyset$-ha?aš-leg-i

3-rain-REC.PAST-IND

'It was raining.'

(Jacobsen 1964, p. 633)

(113) midámaléssay?gi

mi-damal-ess-ay?-i-gi

1SUBJ.2OBJ-hear-NEG-int.past-IND-SUBJ.REL

'I didn't hear you.'

(Jacobsen 1964, p. 636)

(114) yéP̌̌uwe Pluli?išgi

$\emptyset$-ye?eš-uwe?-lul-i?-i-š-gi

3-fly.away-hence-dist.past-ATTR-IND-SR-SUBJ.REL

'He flew away long ago.'

(Jacobsen 1964, p. 636)

As I have shown through my analysis of morphologically tenseless clauses, temporal remoteness morphemes are not required in Washo for achieving past temporal reference. What is noteworthy is that -ujil may co-occur with a temporal remoteness morpheme. For instance, in (115) -uyil co-occurs with the intermediate past -ay?, which is compatible with the reference time set by the context, which is one month before speech time.

(115) a. Context: Your friend was in the hospital last month, but he's ok now.

b. degumyáha PuMánala PéPuyilay?gi

de-gum-yaha ?um-Majal-a P-e?-unil-ay?-i-gi

NMLZ-REFL-hurt NMLZ-building-LOC 3-COP-PAST-INT.PST-IND-SUBJ.REL

Pida wá:din hamu Pánawi

?ida wa:din Ø-hamu-?anaw-i

and now 3-feel-good-IND

'He was in the hospital, and now he's feeling good.'

Recent formal research on temporal remoteness morphemes in other languages has produced mixed results with respect to whether they should be treated as true tenses or not. Cable (2013) argues that temporal remoteness markers in Gĩkũyũ are not true tenses, while Bochnak and Klecha (2015) and Mucha (2015) argue that those in Luganda and Medumba, respectively, can be given analyses as tenses. More research is needed to determine whether these should be analyzed as true tenses or not in Washo. If not, then Washo is a language with one true tense, namely -uyil, which is optional for past time reference. However, if temporal remoteness morphemes can be analyzed as tenses, then Washo not only presents us with an example of an optional tense language, but also a language in which multiple tenses can appear within the same clause. ${ }^{38}$ Although this latter situation is one that has not received much attention in the formal literature, it is perhaps not so surprising that we should find languages

38 Also see Hayashi and Oshima (2015) for a similar phenomenon in South Baffin Inuktitut, and Mucha (2015) for the co-occurrence of temporal remoteness markers and "time of day" markers in Medumba. Klecha and Bochnak (to appear) also show that multiple temporal remoteness markers can occur within a single clause in Luganda, although they argue that each occurrence targets a distinct temporal variable. 
with multiple tenses, when we view tenses as features placing presuppositions on the value of a temporal pronoun. So long as the presuppositions of individual tenses do not conflict, or they place restrictions on distinct variables, there is in principle no reason why multiple tense features in a clause could not co-occur. But much more work needs to be done to investigate this matter in Washo.

Another question for further research is the status of the suffix -uyil on nouns in Washo. Jacobsen (1964) describes this use of -uyil as describing a deceased individual. When attaching to a noun whose referent in the context is known to be alive, it has the force of profanity. Examples of each of these uses are given in (116)-(117).

$$
\begin{array}{ll}
\text { (116) } & \text { diyéyaluPunil } \\
\text { di-yeyalu?-unil } \\
\text { 1.POSS-relative- PAST } \\
\text { 'my dead relatives' } \\
\text { (117) } & \text { sukúku?unil MéPigi } \\
& \text { suku } \sim \text { RED-unil M-e?-i-gi } \\
\text { dog PL- PAST 2-be- IND- SUBJ.REL } \\
\text { 'You damn dogs!' }
\end{array}
$$$$
\text { (Jacobsen 1964, p. 482) }
$$

This fairly narrow range of interpretations of -ujil on nouns potentially points to an analysis where -uyil in these cases is not an instance of nominal tense. However, all the nouns given by Jacobsen are those that denote permanent properties with respect to the lifetime of the individual, which may be the source of the implication that the referent of the noun is deceased when combined with -uyil. A much more systematic investigation of -uyil with a wider variety of nouns is in order before drawing any conclusions about this use of the suffix. In any case, there is somewhat of a debate in the literature over whether grammatical temporal modifiers of nouns should be analyzed as true tenses (Nordlinger and Sadler 2004; Thomas 2014; Tonhauser 2007), so I will not even speculate at this point whether we want to extend the current analysis of -uyil as a past tense to these nominal cases, though it remains an interesting question for future research.

\section{Conclusion}

I have argued that the verbal suffix -uyil in Washo should be analyzed as a past tense, parallel with past tense in English. Strikingly, the interpretation of -uyil is highly similar to that of English past tense, as both give rise to simultaneous and backshifted readings in propositional attitude complements, for instance. Meanwhile, I argued that morphologically tenseless clauses are also semantically tenseless. Within the formal framework adopted, this means that there is no tense feature restricting the value of a temporal pronoun. However, I argued on the basis of back-shifted readings in embedded clauses that a temporal pronoun is still represented in morphologically tenseless clauses. That is, morphologically tenseless clauses lack tense features, but still contain a temporal pronoun. My analysis thus makes precise what it means for a language to have optional tenses, and provides a window into the nature of crosslinguistic variation in the domain of tenses and temporal reference. Specifically, we 
observe that tense need not be an all-or-nothing category, in the sense that tense features may not form complete paradigms in all languages that have tenses. ${ }^{39}$

The results of this paper raise important issues in the analysis of tense and temporal interpretation cross-linguistically. First, instead of the rigid two-way split between tensed versus tenseless languages that we began with at the beginning of the paper, a three-way typology of tense systems emerges. Languages can be morphologically tensed or tenseless, and within the tensed languages, tenses may be obligatory or optional. On the morphological side, this view has already been advanced by Plungian and van der Auwera (2006). A novel contribution of this paper has been to extend this hypothesis to the semantics, where I argued that there is at least one language where semantic tenses are present in some, though not all, finite clauses. Thus, what 'optional tense' means from a semantic point of view is that sometimes a reference time variable is semantically restricted, and sometimes not. In other words, we have found another case of variation in tense systems of the sort that we already knew existed from cross-linguistic research, namely in the means through which a language places restrictions on temporal variables.

Second, the cessation inference associated with - unil (Jacobsen 1964) was shown not to be part of the conventional meaning, but rather a cancellable implicature. Cable (2016) also makes this observation for the optional past in Tlingit. This cross-linguistic finding calls into question Plungian's contention that optional pasts have a semantics distinct from an ordinary past tense in English-like languages, and whether 'discontinuous past' is in fact a linguistic category at all. At the heart of this issue is the lack of paradigmatic opposition between tensed and tenseless forms, and how the shape of tense paradigms affects the interpretation of morphologically tensed and tenseless clauses, both within and across languages. On the one hand, the absence of a full paradigm of tenses gives rise to a cessation inference for sentences containing an overt past tense. On the other hand, morphologically tensed and tenseless clauses do not compete in a Maximize Presupposition-based competition. This latter fact motivated a modification to the traditional definition of MP, where the set of alternatives is crucially relativized to full morphological paradigms. This study in optional tense thus provides a window into the broader issues of presuppositional alternatives, and how the shape of morphological paradigms contributes to semantic interpretation.

Third, this paper offered a novel argument against a phonologically null non-future tense analysis of morphologically tenseless clauses based on the lack of Maximize Presupposition effects. Based on the empirical data alone, I showed that both my analysis and a non-future tense analysis of such clauses in Washo are almost indistinguishable, except for future interpretations of clausal conjunctions with sequential $-u d$, where my analysis fares better. Given the narrow range of data that distinguish the analyses empirically, the new theoretical argument from Maximize Presupposition is welcome, particularly since the analysis of morphologically tenseless clauses cross-linguistically has been the subject of much recent debate. Crucially, this argument is afforded to us by the fact that Washo is an optional tense language. While I believe this argument can in principle be extended to the analysis of other languages with optional tense,

39 An interesting avenue for further research would be to examine other optional syntactic operations, e.g., optional wh-movement, as suggested by a reviewer. 
and also to languages with exclusively morphologically tenseless finite clauses, it is an empirical matter what kind of analysis is appropriate for an individual language.

Finally, the Washo data in this paper contribute to a growing body of work on temporal reference cross-linguistically. While the focus was on past interpretation, this study also raised the issue of future interpretation, particularly for morphologically tenseless clauses. There is much more to be said here, both for Washo and other languages, and there seems to be much important cross-linguistic variation here. First, whereas Washo allows future interpretations of morphologically tenseless clauses in planning contexts, this is not possible in St'át'imcets, where an overt future marker must be used (Lisa Matthewson, p.c.). Under the analysis I presented, this would amount to variation in the availability of a covert PLAN operator. Second, a reviewer notes that future interpretations of morphologically tenseless matrix clauses in Mandarin Chinese can also be licensed by a plan context or a conditional, but non-plan futures require a modal, just like in Washo. However, a future interpretation is also licensed in complement clauses in Mandarin Chinese. This does not seem to be the case for Washo, where a future marker is required for future interpretations of complement clauses, but more work needs to be done here. The nature of future interpretation, and how it differs from past and present interpretation, remains a critical and open issue ripe for further research.

Acknowledgments First and foremost, I would like to thank my Washo consultants, without whom this work would not have been possible: Steven James and the late Ramona Dick. This paper is dedicated to her memory. Thanks to Pranav Anand, Seth Cable, Eva Csipak, Anastasia Giannakidou, Emily Hanink, Vera Hohaus, Chris Kennedy, Peter Klecha, Andrew Koontz-Garboden, Lisa Matthewson, Anne Mucha, Judith Tonhauser, Alan Yu, and Malte Zimmermann for comments on various versions of this work, as well as two anonymous reviewers and associate editor Paul Portner for helping improve this paper. I also thank audiences at the University of California, Berkeley, the University of Göttingen, the University of Manchester, Universitat Pompeu Fabra, the University of Tübingen, CSSP at Universite Paris 7, the Szklarska Poręba Workshop, and SULA9 at UC Santa Cruz, where parts of this work were presented. I gratefully acknowledge funding from the Jacobs Fund of the Whatcom Museum, and a Newton International Fellowship funded by the British Academy and Royal Society. This paper was written while I was a Newton Fellow at the University of Manchester. The usual disclaimers apply.

Open Access This article is distributed under the terms of the Creative Commons Attribution 4.0 International License (http://creativecommons.org/licenses/by/4.0/), which permits unrestricted use, distribution, and reproduction in any medium, provided you give appropriate credit to the original author(s) and the source, provide a link to the Creative Commons license, and indicate if changes were made.

\section{Appendix: Orthography and glossing conventions}

The Washo orthography used in this paper is a modified variant of the one developed by Jacobsen (1964). Most characters have their typical IPA values, with the following exceptions: $L=[1], M=[\mathrm{m}], \breve{s}=\left[\int\right], y=[\mathrm{j}], z=[\widehat{\mathrm{dz}}]$. An acute accent over a vowel indicates stress, and $:$ indicates a long vowel. Morpheme glosses are as follows: 1,2,3 $=1$ st, 2 nd, 3rd person; ATTR = attributive; CAUS = causative; COP = copula; DEP = dependent mood; DIST.PAST = distant past; D.POSS = d-possessive; DU = dual; FUT = future; HUM = human; INCH = inchoative; IND = independent mood; INT.PAST = intermediate past $;$ LOC $=$ locative $;$ MIR $=$ mirative $;$ MOD $=$ modal $;$ NEG $=$ negation; NMLZ = nominalizer; OBJ $=$ obj; OBJ. REL $=$ object relative $;$ PAST $=$ past tense $;$ PL $=$ plural $;$ POSS = possessive $; \mathrm{PRO}=$ pronoun $; \mathrm{PROSP}=$ prospective aspect $; \mathrm{PRT}=$ particle; 
$\mathrm{Q}=$ question; REC.PAST $=$ recent past REFL = reflexive; RESTR = restrictive; $\mathrm{SBJ}=$ subjunctive; $\mathrm{SEQ}=$ sequential; $\mathrm{SR}=$ switch reference; $\mathrm{STATIC}=$ prefix on weather verbs; SUBJ $=$ subject; SUBJ.REL $=$ subject relative; THEME $=$ anaphoric sentence connective theme; VIS = visual evidential.

\section{References}

Abusch, D. (1997). Sequence of tense and temporal de re. Linguistics and Philosophy, 20(1), 1-50. doi:10. 1023/A:1005331423820.

Altshuler, D., \& Schwarzschild, R. (2012). Moment of change, cessation implicatures and simultaneous readings. In E. Chemla, V. Homer, \& G. Winterstein (Eds.), Proceedings of Sinn und Bedeutung 17 (pp. 45-62). http://semanticsarchive.net/sub2012.

Arregui, A., \& Kusumoto, K. (1998). Tense in temporal adjunct clauses. In D. Strolovitch \& A. Lawson (Eds.), Proceedings of semantics and linguistic theory (SALT) (Vol. 8, pp. 1-18). Ithaca, NY: CLC Publications. doi:10.3765/salt.v8i0.2814

Baker, M. C., \& Travis, L. (1997). Mood as verbal definiteness in a 'tenseless' language. Natural Language Semantics, 5, 213-269. doi:10.1023/A:1008262802401.

Bittner, M. (2005). Future discourse in a tenseless language. Journal of Semantics, 22, 339-387. doi:10. 1093/jos/ffh029.

Bittner, M. (2014). Temporality: Universals and variation. Chichester, UK: Wiley Blackwell.

Bochnak, M. R. (2015). Variable force modality in Washo. In T. Bui \& D. Özylldız (Eds.), Proceedings of North-East Linguistics Society 45 (Vol. 1, pp. 105-114). Amherst, MA: GLSA.

Bochnak, M. R., \& Klecha, P. (2015). Temporal remoteness and vagueness in past time reference in Luganda. In Proceedings of 45th annual conference on African linguistics (ACAL).

Bohnemeyer, J. (2002). The grammar of time reference in Yukatek Maya. Munich: Lincom.

Brisson, C. (2003). Plurals, all, and the nonuniformity of collective predication. Linguistics and Philosophy, 26, 129-184. doi:10.1023/A:1022771705575.

Cable, S. (2013). Beyond the past, present, and future: Towards the semantics of 'graded tense' in Gĩkũyũ. Natural Language Semantics, 21, 219-276. doi:10.1007/s11050-012-9092-3.

Cable, S. (2016). The curious implicatures of optional past tense in Tlingit, ms. University of Massachusetts.

Copley, B. (2002). The semantics of the future. PhD thesis, Massachusetts Institute of Technology, Cambridge, MA.

Copley, B. (2008). The plan's the thing: Deconstructing futurate meanings. Linguistic Inquiry, 39(2), 261274. doi:10.1162/ling.2008.39.2.261.

Farkas, D., \& de Swart, H. (2010). The semantics and pragmatics of plurals. Semantics and Pragmatics, 3(Aricle 6), 1-54. doi:10.3765/sp.3.6.

Gennari, S. (2003). Tense meanings and temporal interpretation. Journal of Semantics, 20, 35-71. doi:10. 1093/jos/20.1.35.

Grønn, A., \& von Stechow, A. (2010). Complement tense in contrast: The SOT parameter in Russian and English. Oslo Studies in Language, 2, 109-153. https://www.journals.uio.no/index.php/osla/issue/ view/5.

Hayashi, M., \& Oshima, D. (2015). How multiple past tenses divide the labor: The case of South Baffin Inuktitut. Linguistics, 53(4), 773-808. doi:10.1515/ling-2015-0017.

Heim, I. (1991). Artikel und Definitheit. In A. von Stechow \& D. Wunderlich (Eds.), Semantics: An international handbook of contemporary research (pp. 487-535). Berlin: De Gruyter.

Heim, I. (1994). Comments on Abusch's theory of tense. In H. Kamp (Ed.), Ellipsis, tense, and questions (pp. 143-170). Amsterdam: University of Amsterdam.

Heim, I., \& Kratzer, A. (1998). Semantics in generative grammar. Oxford: Blackwell.

Jacobsen, W. H. (1964). A grammar of the Washo language. PhD thesis, University of California, Berkeley. http://escholarship.org/uc/item/52c6q7hg.

Jacobsen, W. H. (1996). Beginning Washo. Carson City, NV: Nevada State Museum.

Kaufmann, S. (2005). Conditional truth and future reference. Journal of Semantics, 22(3), 231-280. doi:10. 1093/jos/ffh025.

Klecha, P., \& Bochnak, M. R. (to appear). Temporal remoteness and relativity. In Proceedings of NELS46.

Klein, W. (1994). Time in language. New York: Routledge. 
Kratzer, A. (1986). Conditionals. In A. Farley, P. Farley, \& K. E. McCollough (Eds.), Proceedings of Chicago Linguistic Society (Vol. 22, pp. 115-135). Chicago: Chicago Linguistic Society.

Kratzer, A. (1998). More structural analogies between pronouns and tenses. In Proceedings of semantics and linguistic theory (SALT) (Vol. 8). Ithaca, NY: CLC Publications. doi:10.3765/salt.v8i0.2808.

Kratzer, A. (2012). Modals and conditionals: New and revised perspectives. New York: Oxford University Press.

Kubota, Y., Lee, J., Smirnova, A., \& Tonhauser, J. (2009). On the cross-linguistic interpretation of embedded tenses. In A. Riester \& T. Solstad (Eds.), Proceedings of Sinn und Bedeutung (Vol. 13, pp. 307-320). Stuttgart: University of Stuttgart.

Kubota, Y., Lee, J., Smirnova, A., \& Tonhauser, J. (2012). Cross-linguistic variation in temporal adjunct clauses. Cahiers Chronos: Selected proceedings of Chronos (Vol. 8, pp. 141-161). Amsterdam: Rodopi.

Kusumoto, K. (2005). On the quantification over times in natural language. Natural Language Semantics, 13, 317-357. doi:10.1007/s11050-005-4537-6.

Lasersohn, P. (1999). Pragmatic halos. Language, 75(3), 522-551.

Leer, J. (1991). The schetic categories of the Tlingit verb. PhD thesis, University of Chicago, Chicago.

Lin, J. (2006). Time in a language without tense: The case of Chinese. Journal of Semantics, 23, 1-53. doi:10.1093/jos/ffh033.

Matthewson, L. (2006). Temporal semantics in a superficially tenseless language. Linguistics and Philosophy, 29, 673-713. doi:10.1007/s10988-006-9010-6.

Mucha, A. (2013). Temporal interpretation in Hausa. Linguistics and Philosophy, 36, 371-415. doi:10. 1007/s10988-013-9140-6.

Mucha, A. (2015). Temporal interpretation and cross-linguistic variation. PhD thesis, University of Potsdam, Potsdam, Germany.

Nordlinger, R., \& Sadler, L. (2004). Nominal tense in crosslinguistic perspective. Language, 80(4), 776-806. doi:10.1353/lan.2004.0219.

Ogihara, T. (1989). Temporal reference in English and Japanese. PhD thesis, University of Texas, Austin.

Partee, B. (1973). Some structural analogies between tenses and pronouns in English. Journal of Philosophy, 70(18), 601-609. doi:10.2307/2025024.

Percus, O. (2006). Anti-presuppositions. In A. Ueyama (Ed.), Theoretical and empirical studies of reference and Anaphora: Toward the establishment of generative grammar as an empirical science (pp. 52-73). Report of the Grant-in-Aid for Scientific Research (B), Project No. 15320052, Japan Society for the Promotion of Science, Washington, DC.

Plungian, V., \& van der Auwera, J. (2006). Towards a typology of discontinuous past marking. Sprachtypologie und Universalienforschung, 59(4), 317-349. doi:10.1524/stuf.2006.59.4.317.

Portner, P. (1998). The progressive in modal semantics. Language, 74(4), 760-787.

Reichenbach, H. (1947). Elements of symbolic logic (pp. 287-298). New York: The Macmillan Company.

Sauerland, U. (2002). The present tense is vacuous. Snippets, 6, 12-13. http://www.ledonline.it/snippets/.

Sauerland, U., Andersen, J., \& Yatsushiro, K. (2005). The plural is semantically unmarked. In S. Kepser \& M. Reis (Eds.), Linguistic evidence (pp. 413-434). Berlin: Mouton de Gruyter.

Schlenker, P. (2012). Maximize presupposition and Gricean reasoning. Natural Language Semantics, 20, 391-429. doi:10.1007/s11050-012-9085-2.

Sharvit, Y. (2003). Embedded tense and universal grammar. Linguistic Inquiry, 34, 669-681. doi:10.1162/ ling.2003.34.4.669.

Sharvit, Y. (2014). On the universal principles of tense embedding: The lesson from before. Journal of Semantics, 31, 263-313. doi:10.1093/jos/ffs024.

Singh, R. (2011). Maximize presupposition and local contexts. Natural Language Semantics, 19, 149-168. doi:10.1007/s11050-010-9066-2.

Smith, C., \& Erbaugh, M. (2005). Temporal interpretation in Mandarin Chinese. Linguistics, 43(4), 713756. doi:10.1515/ling.2005.43.4.713.

Smith, C., Perkins, E., \& Fernald, T. (2007). Time in Navajo: Direct and indirect interpretations. International Journal of American Linguistics, 73(1), 40-71. doi:10.1086/518334.

Stowell, T. (2007). The syntactic expression of tense. Lingua, 117, 437-463. doi:10.1016/j.lingua.2005.08. 003.

Thomas, G. (2014). Nominal tense and temporal implicatures: Evidence from Mbyá. Natural Language Semantics, 22(4), 357-412. doi:10.1007/s11050-014-9108-2. 
Thomas, G. (2015). The present tense is not vacuous. Journal of Semantics, 32(4), 685-747. doi:10.1093/ jos/ffu010.

Thomason, R. (1970). Indeterminist time and truth-value gaps. Theoria, 36(3), 264-281. doi:10.1111/j. 1755-2567.1970.tb00427.x.

Thomason, R. (1984). Combinations of tense and modality. Handbook of Philosophical Logic, 2, $135-165$.

Tonhauser, J. (2007). Nominal tense? The meaning of guaraní nominal temporal markers. Language, 83(4), 831-869. doi:10.1353/lan.2008.0037.

Tonhauser, J. (2011). Temporal reference in Paraguayan Guaraní, a tenseless language. Linguistics and Philosophy, 34(3), 257-303. doi:10.1007/s10988-011-9097-2.

Tonhauser, J. (2015). Cross-linguistic temporal reference. Annual Review of Linguistics, 1, 129-154. doi:10. 1146/annurev-linguist-030514-124923.

Toosarvandani, M. (to appear). The temporal interpretation of clause chaining in Northern Paiute. Language. 